\title{
Quantitation of small intestinal permeability during normal human drug absorption
}

\author{
David G Levitt
}

\begin{abstract}
Background: Understanding the quantitative relationship between a drug's physical chemical properties and its rate of intestinal absorption (QSAR) is critical for selecting candidate drugs. Because of limited experimental human small intestinal permeability data, approximate surrogates such as the fraction absorbed or Caco-2 permeability are used, both of which have limitations.

Methods: Given the blood concentration following an oral and intravenous dose, the time course of intestinal absorption in humans was determined by deconvolution and related to the intestinal permeability by the use of a new 3 parameter model function ("Averaged Model" (AM)). The theoretical validity of this AM model was evaluated by comparing it to the standard diffusion-convection model (DC). This analysis was applied to 90 drugs using previously published data. Only drugs that were administered in oral solution form to fasting subjects were considered so that the rate of gastric emptying was approximately known. All the calculations are carried out using the freely available routine PKQuest Java (www.pkquest.com) which has an easy to use, simple interface.
\end{abstract}

Results: Theoretically, the AM permeability provides an accurate estimate of the intestinal DC permeability for solutes whose absorption ranges from $1 \%$ to $99 \%$. The experimental human AM permeabilities determined by deconvolution are similar to those determined by direct human jejunal perfusion. The small intestinal pH varies with position and the results are interpreted in terms of the $\mathrm{pH}$ dependent octanol partition. The permeability versus partition relations are presented separately for the uncharged, basic, acidic and charged solutes. The small uncharged solutes caffeine, acetaminophen and antipyrine have very high permeabilities (about $20 \times 10^{-4} \mathrm{~cm} / \mathrm{sec}$ ) corresponding to an unstirred layer of only $45 \mu \mathrm{m}$. The weak acid aspirin also has a large AM permeability despite its low octanol partition at pH 7.4, suggesting that it is nearly completely absorbed in the first part of the intestine where the $\mathrm{pH}$ is about 5.4.

Conclusions: The AM deconvolution method provides an accurate estimate of the human intestinal permeability. The results for these 90 drugs should provide a useful benchmark for evaluating QSAR models.

\section{Background}

Despite the multitude of publications describing the different factors that affect the rate of intestinal absorption of drugs, there is only limited experimental data for the human small intestinal permeability of the thousands of drugs that are orally absorbed. The quantitative structure activity relationship (QSAR) between a drug's physical chemical properties and its rate of intestinal absorption is obviously of great importance in selecting candidate

Correspondence: levit001@umn.edu

Department of Integrative Biology and Physiology, University of Minnesota, 6-125 Jackson Hall, 321 Church St. S. E, Minneapolis, MN 55455, USA drugs. The standard approach is to relate some property of the drug (e.g. octanol/water partition, Caco-2 cell permeability, etc.) to the fraction absorbed in humans $[1,2]$. Although the fraction absorbed is a useful clinical parameter [3], it is a crude measure of permeability. Since most successful drugs are nearly $100 \%$ absorbed, they cannot provide any quantitative data about their relative permeability. Furthermore, the fraction absorbed may be influenced in uncertain ways by factors such as intestinal metabolism or large intestinal absorption.

More recently, there have been direct measurements of human small intestinal permeability using the regional perfusion technique. In a recent communication, Dahan,

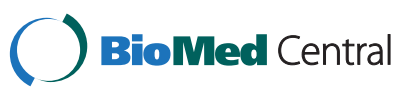


Lennernas and Amidon [4] discuss the various reasons why these measurement of "...jejunal permeability (alone) may not always adequately predict" the fraction absorbed. This includes small intestinal heterogeneity (such as variations in $\mathrm{pH}$ and membrane transport systems) and large intestinal absorption. In addition, the regional perfusion conditions used in these measurements may differ from the normal physiological conditions. For example, the high pressure and volume in the perfusion system may increase access to the intervillous space allowing increased paracellular transport of PEG markers [5].

This paper describes a new approach to measuring human intestinal permeability during normal drug absorption. It is well recognized that the time course of intestinal absorption can be determined from deconvolution of the plasma concentrations following oral and intravenous input in the same subject. There are a variety of mathematical approaches to this deconvolution [6]. Some care is required in this procedure because random errors in the plasma concentration data can lead to non-physiological fluctuations or negative values in the predicted absorption rate. The simplest procedures assume that the absorption can be described by some simple function (e.g. 3 parameter gamma [6] or Hill function [7]) which is then adjusted to give the best fit to the oral plasma absorption curve. More sophisticated approaches use generalized functions with varying numbers of parameters $[8,9]$. This absorption function must then be interpreted in terms of the intestinal permeability. This is difficult because intestinal transit, dispersion and absorption is complicated and poorly understood. The most widely used quantitative model of intestinal absorption is the "compartmental absorption and transit" (CAT) model which has been incorporated into the commercial program GastroPlus $^{\text {th }}[10,11]$. This CAT model describes the small intestine in terms of 7 sequential well mixed compartments with passive absorption (determined by the permeability) and one way transport in the aboral direction. Because the solution of this model's equations requires numerical calculations and does not have an analytical solution, it cannot be easily adapted for the deconvolution approach.

In this paper a new 3 parameter function ("Averaged Model" (AM)) that accurately mimics the transit, dispersion and absorption of the small intestine is used to determine the intestinal permeability by deconvolution. The range of validity of this AM model is evaluated by comparing it with the more exact diffusion convection model (DC). This AM procedure is then applied to published data to determine the human intestinal permeability of 90 drugs. The main criterion for the selection of drugs for this analysis is that they were administered as an oral solution in order to eliminate the ambiguity and variability in the rate of gastric emptying.

\section{Methods}

\section{Numerical solution of the Diffusion-Convection (DC)} model equations

Ni et. al. [12] have described a model of intestinal transit which combines convection, dispersion and absorption (DC model). The main assumption is that there is an equal volume flow into and out of each intestinal region so that the cross-sectional area (radius $=r$ ) and the convective flow (F) remains constant as the solute spreads along the intestine by convection and dispersion. The differential equation describing this DC model is:

$$
\pi r^{2} \frac{\partial c}{\partial t}=\pi r^{2} D \frac{\partial^{2} c}{\partial x^{2}}-F \frac{\partial c}{\partial x}-2 \pi r P c
$$

The left hand side is the time dependent change in the concentration $\mathrm{c}(\mathrm{x}, \mathrm{t})$ (where $\mathrm{x}$ is the distance from the pyloric sphincter). The first term on the right is the dispersive mixing, the second is the convective flow and the third is the absorption term where $r$ is the intestinal radius $(\mathrm{cm}), \mathrm{D}$ is the dispersion coefficient $\left(\mathrm{cm}^{2} / \mathrm{sec}\right), \mathrm{F}$ is the volume flow $\left(\mathrm{cm}^{3} / \mathrm{sec}\right)$ and $\mathrm{P}$ is the permeability $(\mathrm{cm} / \mathrm{sec})$.

$\mathrm{Ni}$ et. al. [12] derived an exact analytical solution to Equation (1) that assumes as a boundary condition an exponential concentration at $\mathrm{x}=0$. This condition is not physiological because it implies that, in addition to the convective flux out of the stomach, there is also a nonphysiological dispersive flux both out of and into the stomach (and out of and into the large intestine). For this reason the analytical solution will not be used here and, instead, a finite difference numerical approximation to Equation (1) will be used in which there is only a convective flux from the stomach to the small intestine and from the small intestine to the large intestine. (Also, the numerical solution is computationally much faster than the analytical solution). The small intestine is divided into $\mathrm{N}$ equal sections with the following difference equations:

$$
\begin{aligned}
& i=1: \quad \Delta V \frac{d c[1]}{d t}=I_{G}(t)-(F+\Delta P+D e) c[1]+\operatorname{Dec}[2] \\
& \begin{aligned}
0<i<N: \quad \Delta V \frac{d c[i]}{d t}= & (F+D e) c[i-1]-(F+\Delta P+2 D e) c[i] \\
& \quad+D e c[i+1]
\end{aligned} \\
& i=N: \quad \Delta V \frac{d c[N]}{d t}=(F+D e) c[N-1]-(F+D e+\Delta P) c[N]
\end{aligned}
$$

where $\mathrm{c}[\mathrm{i}]$ is the concentration in the ith compartment at time $t, I_{G}(t)$ is the rate of gastric emptying into the intestine, $\mathrm{r}=$ intestinal radius, $\mathrm{L}=$ intestinal length, $\mathrm{S}=$ surface area $=2 \pi \mathrm{rL}, \mathrm{V}=$ volume $=\pi \mathrm{r}^{2} \mathrm{~L}, \Delta \mathrm{P}=\mathrm{PS} / \mathrm{N}$, $\Delta \mathrm{V}=\mathrm{V} / \mathrm{N}$ and $\mathrm{De}=\pi^{2} \mathrm{DN} / \mathrm{L}$. The rate $\mathrm{E}_{\mathrm{DC}}(\mathrm{t})$ that the 
unabsorbed solute exits the small intestine and passes into the large intestine is:

$$
E_{D C}(t)=F c[N]
$$

The cumulative amount $A_{D C}\left(t_{i}\right)$ that has entered the large intestine at time $t_{i}=i \Delta t$ is:

$$
A_{D C}\left(t_{i}\right)=\sum_{j=1}^{i} E_{D C}\left(t_{j}\right) \Delta t
$$

The absorption rate $R_{D C}(t)$ at time $t_{i}$ is:

$$
R_{D C}\left(t_{i}\right)=\Delta P \sum_{i=1}^{N} c[i]
$$

Gastric emptying in humans of non-caloric fluids is approximately exponential with a half time of about 15 minutes $[13,14]$ and it will be assumed that $\mathrm{I}_{\mathrm{G}}(\mathrm{t})$ is exponential:

$$
I_{G}(t)=F C_{0} \exp \left(-t / T_{G}\right)
$$

where $T_{G}$ is the time constant for gastric emptying, $C_{0}$ is the gastric concentration at $\mathrm{t}=0$ and $\mathrm{FC}_{0}=\mathrm{Dose} / \mathrm{T}_{\mathrm{G}}$. In addition, the parameters $\mathrm{D}, \mathrm{F}$ and $\mathrm{P}$ will be described in terms of 3 other time constants:

$$
T_{P}=r /(2 P) \quad T_{F}=V / F \quad T_{D}=L^{2} /(2 D)
$$

Equation (2) is solved numerically using $\mathrm{N}=50$ and the Rosenbrock method as implemented in Maple (Maplesoft ${ }^{\mathrm{Tm}}$ ). Some of the figures shown here are Maple plots.

\section{Derivation and description of the "Averaged Model (AM)"}

The DC equation (Equation (1)) has the interesting property that, if the drug is completely absorbed in the small intestine and the amount entering the large intestine can be neglected, it has the same kinetics as a well stirred compartment. This can be seen by integrating Equation (1) over $\mathrm{x}$ from 0 (pyloric sphincter) to $\mathrm{x}=\mathrm{L}$ (the ileocecal junction):

$$
\begin{gathered}
\pi r^{2} L \frac{d C}{d t}=I_{0}(t)-I_{L}(t)-2 \pi r L P C \\
C=(1 / L) \int_{0}^{L} c(x, t) d x I_{0}(t)=-\pi r^{2} D \frac{d c(0, t)}{d x}+F c(0, t) \\
I_{L}(t)=-\pi r^{2} D \frac{d c(L, t)}{d x}+F c(L, t)
\end{gathered}
$$

where $C$ is the average intestinal concentration and $I_{0}(t)$ and $\mathrm{I}_{\mathrm{L}}(\mathrm{t})$ are the inflow and outflow rates. If the outflow term $I_{L}(t)$ is negligible, then this equation reduces to:

$$
V \frac{d C}{d t}=I_{0}(t)-P S C
$$

This is identical to the case of a well mixed compartment of volume $\mathrm{V}$ with arbitrary input $\mathrm{I}_{0}(\mathrm{t})$. Assuming that $\mathrm{I}_{0}(\mathrm{t})=\mathrm{I}_{\mathrm{G}}(\mathrm{t})$ (Equation (6)) and solving the differential Equation (9) one obtains the "averaged model" (AM) equation for the case of $100 \%$ absorption:

$$
C(t)=(\text { Dose } / V) T_{P}\left[\exp \left(-t / T_{G}\right)-\exp \left(-t / T_{P}\right)\right] /\left(T_{G}-T_{P}\right)
$$

where $T_{P}$ and $T_{G}$ are the permeability and gastric emptying time constants (Equation (6) and (7)). The rate of absorption $(\mathrm{R}(\mathrm{t}))$ from the small intestine is:

$$
R(t)=P S C(t)=\text { Dose }\left[\exp \left(-t / T_{G}\right)-\exp \left(-t / T_{P}\right)\right] /\left(T_{G}-T_{P}\right)
$$

This $A M R(t)$ is identical to the absorption rate for the DC model for the case where all the solute is absorbed $\left(\mathrm{I}_{\mathrm{L}}(\mathrm{t})=0\right.$, Equation (8)). It should be emphasized that although Equation (9) is similar to the well-mixed equation it is not physically equivalent because $C$ is the average concentration and it is not assumed that the intestine is well mixed. For example, it would be erroneous to assume that the rate of solute flow into the large intestine was equal to $\mathrm{F}^{*} \mathrm{C}$.

As discussed above, Equation (11) is a rigorously accurate description of the intestinal absorption for the DC model only for the case where all of the solute is absorbed in the small intestine. This result can be generalized to the arbitrary permeability case where only a fraction $\mathrm{F}_{\mathrm{A}}$ of the total Dose is absorbed in the small intestine:

$$
\begin{aligned}
& R_{M}(t)=M\left[\exp \left(-t / T_{G}\right)-\exp \left(-t / T_{P}\right)\right] /\left(T_{G}-T_{P}\right) \\
& M=F_{A} \text { Dose }
\end{aligned}
$$

where $M$ is the total amount absorbed. In addition, the relationship between $T_{P}$ and $P$ must be modified for this general case. The $\mathrm{C}$ in Equation (8) is based on the assumption of $100 \%$ absorption. If, for example, only $50 \%$ were absorbed the actual concentration would be twice this value of $\mathrm{C}$ and the value of $\mathrm{P}$ would be reduced by half. Thus, the general relationship between $T_{P}$ and the averaged model intestinal permeability $\left(\mathrm{P}_{\mathrm{M}}\right)$ is:

$$
P_{M}=F_{A} P=F_{A} r /\left(2 T_{P}\right)
$$

The amount absorbed $\left(\mathrm{A}_{\mathrm{M}}(\mathrm{t})\right)$ as a function of time is:

$$
\begin{aligned}
A_{M}(t)= & \int_{0}^{t} R_{M}(\tau) d t=M\left\{1+\left[T_{P} \exp \left(-t / T_{P}\right)\right.\right. \\
& \left.\left.-T_{G} \exp \left(-t / T_{G}\right)\right] /\left(T_{G}-T_{P}\right)\right\}
\end{aligned}
$$

These AM model expressions for the intestinal absorption rate $R_{M}(t)$ and $P_{M}$ are only approximations to the exact DC model for this general case where not all the 
solute is absorbed. The range of validity of this approximation will be evaluated by comparing it to the DC model for a range of experimental parameters (see Results, Comparison of DC and AM models).

$R_{M}$ and $M$ represent the rate and total amount absorbed across the small intestinal epithelial luminal membrane. Assuming a linear system, the rate of solute entering the systemic circulation $\left(R_{S M}\right)$ is:

$$
\begin{aligned}
& R_{S M}(t)=M_{S}\left[\exp \left(-t / T_{G}\right)-\exp \left(-t / T_{P}\right)\right] /\left(T_{G}-T_{P}\right) \\
& M_{S}=F_{A}\left(1-E_{H}\right)\left(1-E_{I}\right) \text { Dose }
\end{aligned}
$$

where $E_{H}$ and $E_{I}$ are the hepatic and intestinal extraction ratios [15]. The hepatic extraction $\left(E_{H}\right)$ can be estimated from the liver blood flow $\left(\mathrm{Q}_{\mathrm{H}}\right)$ [15] and the whole blood liver clearance $\left(\mathrm{Cl}_{\mathrm{H}}\right)$ :

$$
E_{H}=C l_{H} / Q_{H}
$$

The liver clearance $\left(\mathrm{Cl}_{\mathrm{H}}\right)$ was estimated by correcting the whole blood clearance following the IV infusion for the fractional renal clearance using data obtained in the same subjects that were used for the permeability estimates.

Equation (15) is a simple 3 parameter function whose parameters $\left(\mathrm{M}_{\mathrm{S}}, \mathrm{T}_{\mathrm{G}}\right.$ and $\left.\mathrm{T}_{\mathrm{P}}\right)$ can be determined experimentally by deconvolution (see below for details) of the blood concentration time course following IV and oral doses. The fraction absorbed $\left(\mathrm{F}_{\mathrm{A}}\right)$ can be determined from $M_{S}$ and estimates of $E_{H}$ and $E_{I}$ (Equation (15)). Finally, the AM model intestinal permeability $\left(\mathrm{P}_{\mathrm{M}}\right)$ can be determined from $\mathrm{F}_{\mathrm{A}}$ and $\mathrm{T}_{\mathrm{P}}$ (Equation (13)).

Equation (15) is symmetrical in $\mathrm{T}_{G}$ and $\mathrm{T}_{\mathrm{P}}$ so that there is an ambiguity in distinguishing the gastric emptying time constant $\mathrm{T}_{\mathrm{G}}$ from the permeability time constant $T_{P}$. Most of the applications described here will be based on data obtained using oral solutions (not tablets) given to fasting subjects and the time constant that is closest to 10 to 15 minutes will be assumed to be $T_{G}$.

The theoretical accuracy of the AM model absorption rate RM (Equation 12) was evaluated by comparing it with the exact DC model $R_{\mathrm{DC}}$ (Equation 5). A set of the $7 \mathrm{DC}$ parameters (Dose, $\left.T_{G}, T_{P}, T_{F}, T_{D}, r, L\right)$ were selected and the DC model intestinal absorption rate and fraction absorbed was determined. Then, the AM model parameters $\left(\mathrm{M}, \mathrm{T}_{\mathrm{G}}, \mathrm{T}_{\mathrm{B}}\right.$ Equation (12)) that provided the best fit to the $\mathrm{DC}$ absorption rate were determined by minimizing the following error function using the optimization routine in Maple (Maplesoft $\left.\mathrm{ft}^{\mathrm{m}}\right)$ :

$$
\text { Error }=(1 / N) \sum_{i=1}^{N}\left(R_{D C}[i]-R_{M}\left(t_{i}\right)\right)^{2}
$$

where $t_{i}=i \Delta t$ and comparing the AM model parameters $\left(\mathrm{F}_{\mathrm{A}}, \mathrm{T}_{\mathrm{P}}\right.$ and $\left.\mathrm{T}_{\mathrm{G}}\right)$ with the actual input $\mathrm{DC}$ parameters.
Experimental determination of the averaged model (AM) parameters by deconvolution

The determination of the $3 \mathrm{AM}$ model parameters $\left(\mathrm{M}_{\mathrm{S}}\right.$, $\mathrm{T}_{\mathrm{G}}$ and $\mathrm{T}_{\mathrm{P}}$ ) is based on standard procedures that have been described previously [6]. First, the 2 or 3 exponential systemic bolus response function $r(t)$ is determined from the experimental blood concentration time course following the known IV infusion. The blood concentration $\mathrm{C}_{\text {oral }}(\mathrm{t})$ following the oral dose is equal to the convolution of $r(t)$ and the AM model systemic absorption rate $R_{S M}(t)$ (Equation (15)):

$$
C_{\text {oral }}(t)=\int_{0}^{t} r(t-\tau) R_{S M}(\tau) d \tau
$$

The 3 AM model parameters $\left(\mathrm{M}_{\mathrm{S}}, \mathrm{T}_{\mathrm{G}}\right.$ and $\left.\mathrm{T}_{\mathrm{P}}\right)$ are then estimated by finding the parameter set that minimizes the error function:

$$
\text { Err }=\sum_{k} \frac{\left|C_{\text {oral }}\left(t_{k}\right)-C_{k}\right|}{C_{k}+\text { noise }}
$$

where $C_{k}$ is the experimental blood concentration at time $t_{k}$ following the oral dose. The "noise" determines the relative weighting of each data point and can be arbitrarily adjusted but is usually set to $10 \%$ of the average blood value. The optimized set of parameters is determined by a non-linear Powell minimization routine [16]. Most of the drugs were administered as oral solutions in fasting subjects and $T_{G}$ was forced to be in the range of 10 to 20 minutes (the normal range for non-caloric fluids $[13,14])$ and only the two parameters $T_{P}$ and $M_{S}$ were freely adjusted. For a few solutes that were administered as capsules or tablets, all 3 parameters were adjusted.

These procedures have been implemented in PKQuest Java, a freely distributed software program that has been used previously for pharmacokinetic analysis of more than 30 different solutes in a series of publications [7]. The implementation is designed to be user friendly and simple to use. The user only needs to enter 1 ) the dose and duration of the constant IV infusion; 2) the experimental blood concentration for the IV dose (which can be copied and pasted from a standard Excel file); and 3) the experimental blood concentration following the oral dose. The program then finds the optimum set of AM parameters. It also outputs 4 plots that are useful for evaluating the results: 1 ) A comparison of the experimental blood concentration for the IV dose versus the blood concentration predicted by bolus response function (there is usually nearly perfect agreement). 2) The AM model absorption rate as a function of time; 3) AM total absorption as a function of time; and 4) a comparison of the experimental blood concentration following the oral dose versus the AM model 
prediction (Equation (18)). This last plot is especially useful because it provides the best measure of the quality of the AM model. See Figures 1, 2, 3 and 4 for examples of these plots. PKQuest Java and a detailed tutorial can be freely downloaded from www.pkquest.com. Also available for download are the complete data sets for the 90 solutes

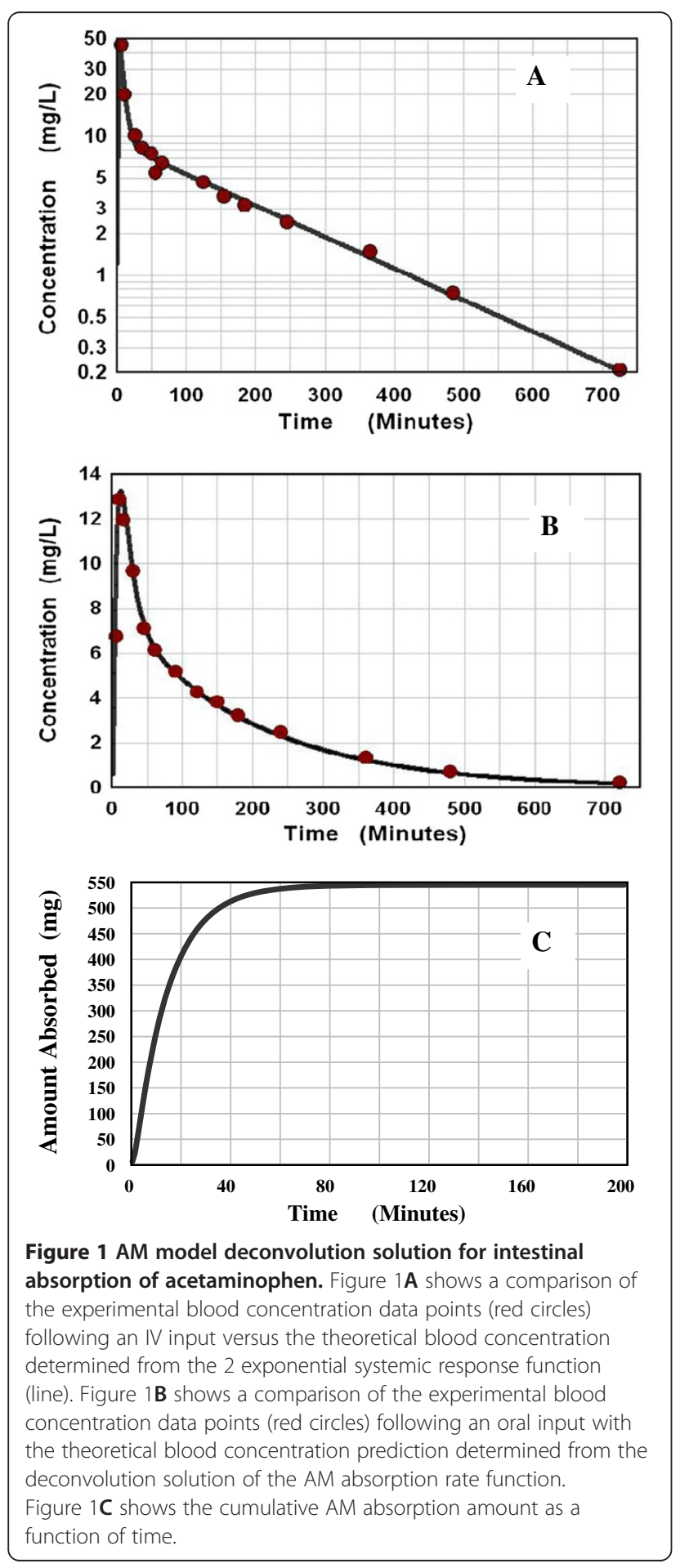

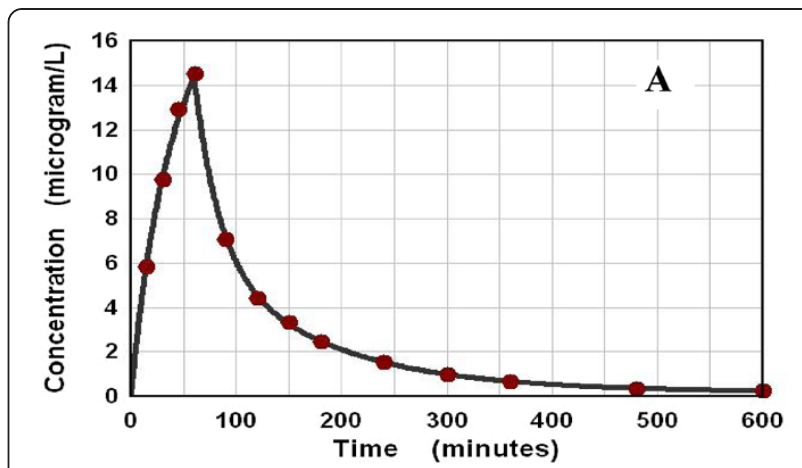
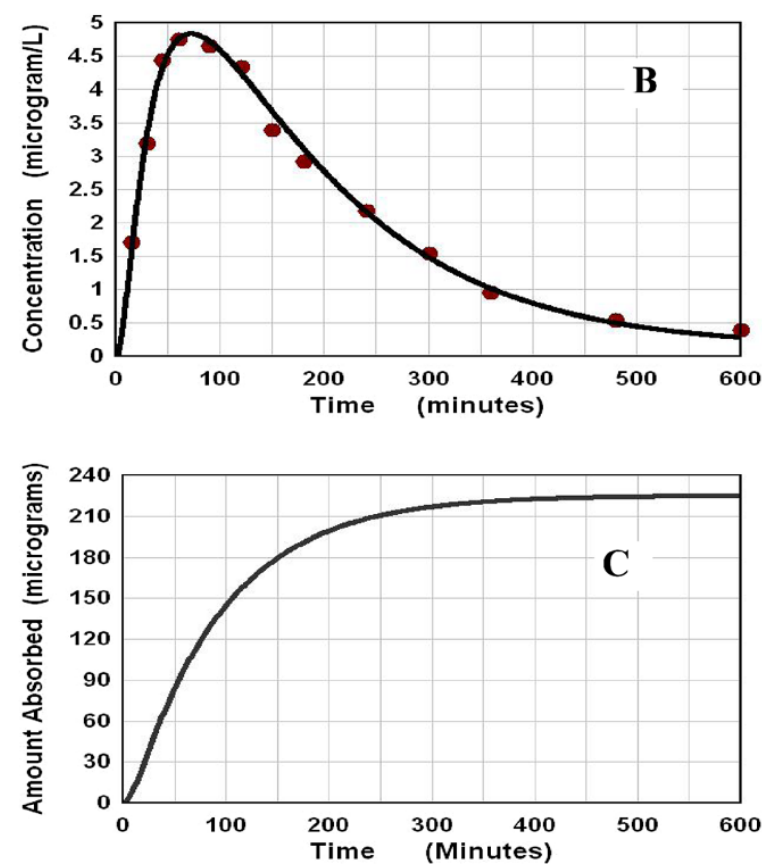

Figure $2 \mathrm{AM}$ model deconvolution solution for intestinal absorption of risedronate. See Figure 1 for details.

discussed in this paper. This allows the user to reproduce all of the results.

\section{Experimental intestinal absorption data}

In order to be a candidate for determination of intestinal permeability it was required that the solute met the following 4 conditions: 1 ) intravenous and oral dose pharmacokinetics in the same subject; 2) the oral dose was in the form of a solution (not tablet) to fasting subjects; 3 ) the drug's pharmacokinetics are linear, at least in the concentration range that is investigated; 4) the drug is soluble at the concentrations used in the absorption study. These conditions severely limit the number of experimental results that can be used. Condition \#1 is satisfied in only a small fraction of permeability studies. Condition \#2 also severely restricts the number of possible candidates because tablets or capsules are used in most oral drug studies. A thorough search of the published 


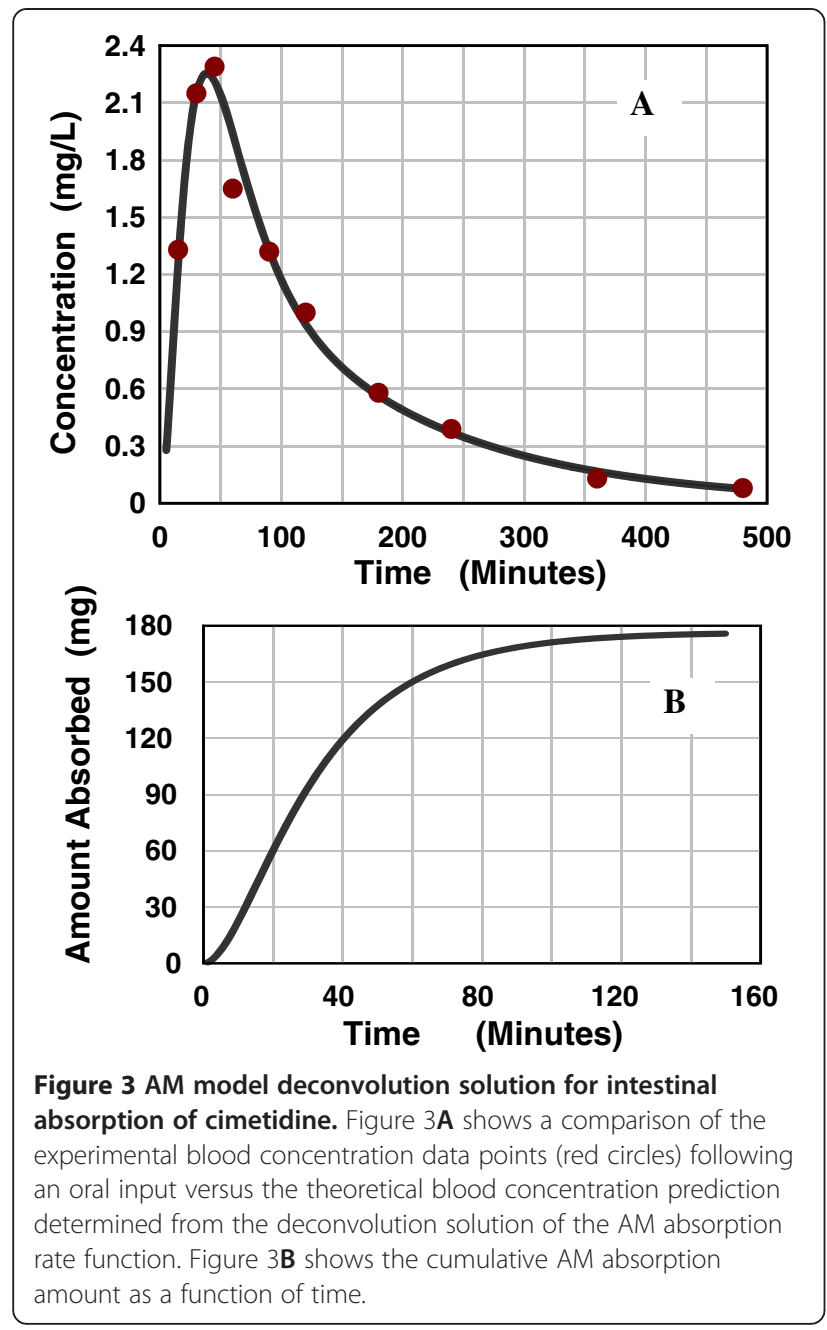

literature returned 90 drugs that met these conditions. A few drugs that were administered as tablets have been included if the drug had a high water solubility so that the tablet would be rapidly dissolved and a low permeability (long $\mathrm{T}_{\mathrm{P}}$ ) that could not be confused with the $\mathrm{T}_{\mathrm{G}}$. The results and analyses are summarized in the Excel file that is included in the Additional file 1: "Table 2". Additional file 1: Table 2 lists the solute, a link to the reference publication, the AM model parameters, a subjective measure of the quality of the AM fit to the data and the calculated permeability. The table includes the ionization behavior of the solute (weak acid, base, neutral or always ionized) in the $\mathrm{pH}$ range of 4 to 8 and the $\mathrm{pKa}$ if it is a weak base or acid. Also listed is an estimate of the experimental $\log$ (octanol/water) partition coefficient at $\mathrm{pH} 7.4(\log \mathrm{D})$. For most solutes there are multiple reported values of $\log \mathrm{D}$ that can vary by as much a $\log$ unit. For those solutes which are available on the LOGKOW site maintained by James Sangster, the value listed is an approximate average of the listed values. When necessary, the log Pow values were converted from $\mathrm{pH} 1$ to a different $\mathrm{pH} 2$ using the following relations (this assumes that only the neutral solute has a finite octanol partition) [17]:

$$
\begin{aligned}
& \text { Mono protic base : } \log \text { Pow }_{2}=\log \text { Pow }_{1}+\log \left(1+10^{(p K a-p H 1)}\right) \\
& -\log \left(1+10^{(p k a-p H 2)}\right) \\
& \text { Monoproticacid : } \log \text { Pow }_{2}=\log \text { Pow }_{1}+\log \left(1+10^{(p H 1-p K a)}\right) \\
& -\log \left(1+10^{(p H 2-p K a)}\right)
\end{aligned}
$$

The experimental perfused human jejunum permeability [18] and the Caco-2 permeability are also listed in Additional file 1: Table 2 if they were available. The form of the oral dose (solution, tablet, capsule) is listed and solutes which may have solubility limitations are marked in the table. If there is suggestive evidence that the intestinal absorption is protein mediated (either influx or efflux), this is also indicated. The experimental data points

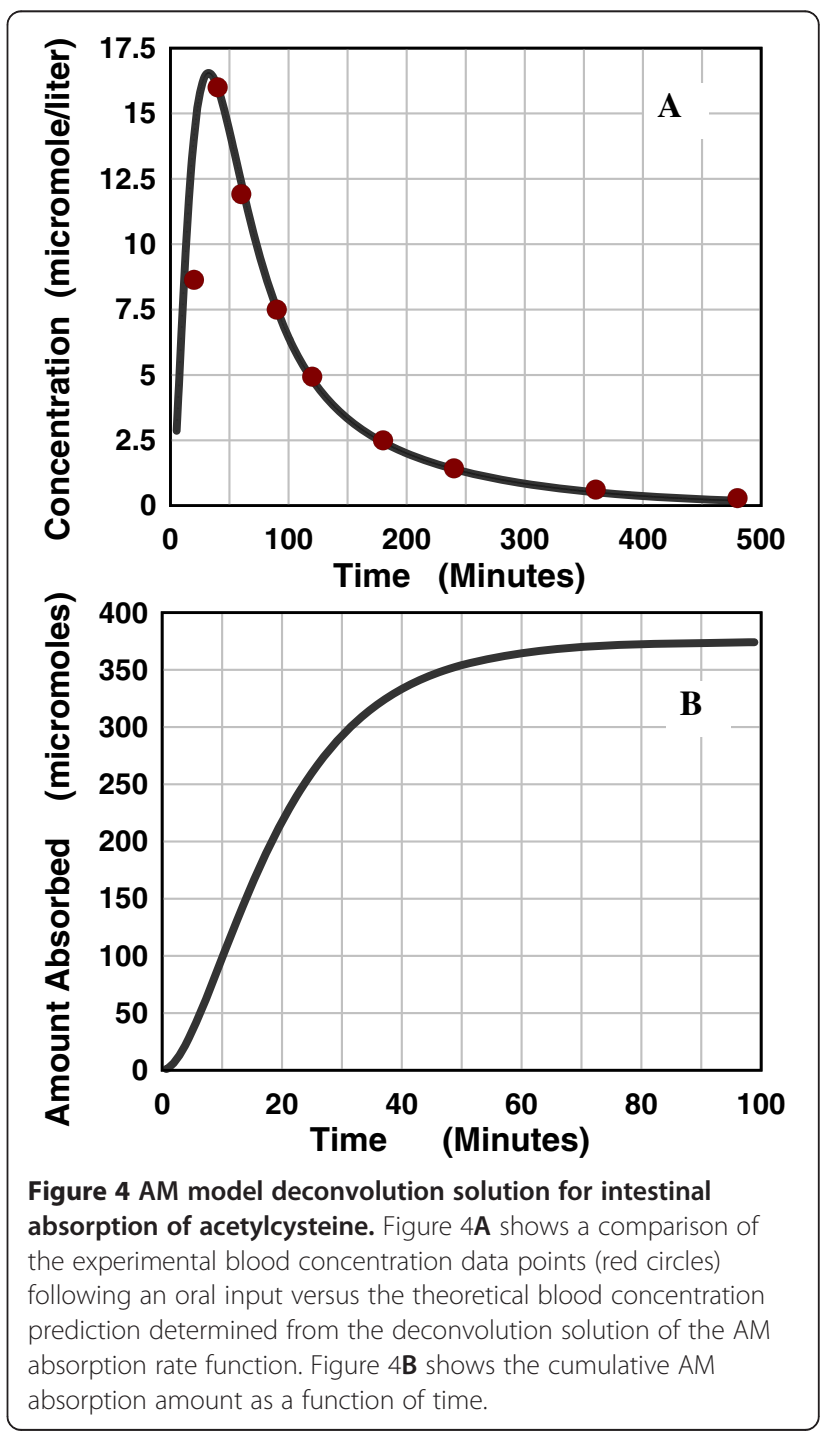



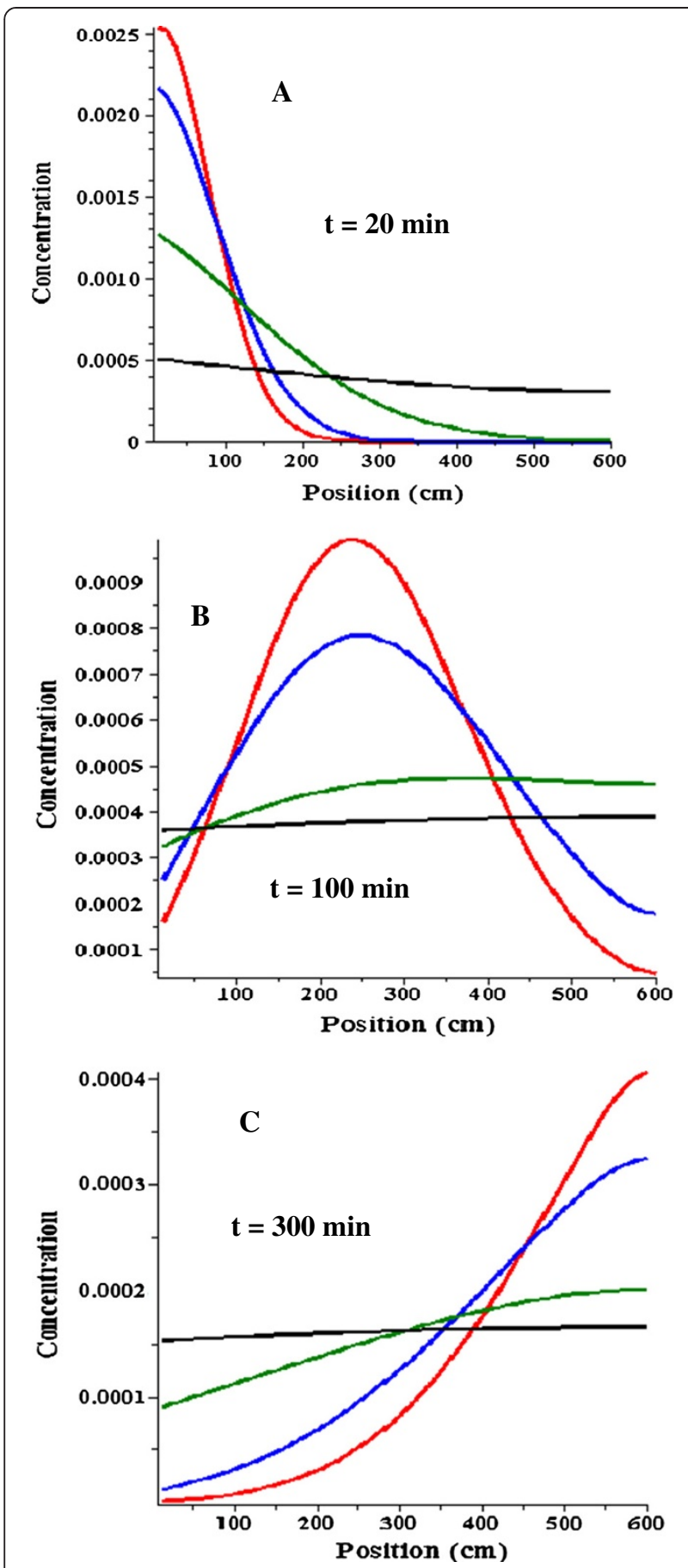

Figure 5 Diffusion convection concentration profile. The diffusion convection model concentration as a function of distance from the pyloric sphincter is shown at 20 (Figure 5A), 100 (B) and 300 minutes (C) after administering the oral dose as a bolus to the stomach for an impermeable $(P=0)$ solute. The profile is shown for 4 different values of the dispersion time constant $\left(T_{D}\right): 2000$ (red); 1000 (blue); 200 (green); and 20 minutes (black). For all profiles $T_{F}=$ 200 minutes; $T_{G}=15$ minutes; $r=1 \mathrm{~cm} ; L=600 \mathrm{~cm}$ and Dose $=1$. were read from the published figures using UN-SCAN-IT (Silk Scientific Corporation).

\section{Results}

Solution and parameter study of the Diffusion-Convection (DC) model

The DC model differential equation (Equation (2)) was solved numerically. Figure 5A, B and $C$ show the DC concentration profile for a non-permeable $(\Delta \mathrm{P}=0)$ solute at time $=20,100$ and 300 minutes after the oral dose with $T_{D}$ (dispersive transit time) values of 2000 (red curve), 1000 (blue), 200 (green) and 20 (black) minutes. Unless otherwise stated, all of the plots described here have $\mathrm{T}_{\mathrm{G}}=15$ minutes (gastric emptying time constant), $\mathrm{T}_{\mathrm{F}}=240$ minutes (convective small intestinal transit time), $\mathrm{N}=50$ (there is no significant change in the results for greater $\mathrm{N}$ ), $\Delta \mathrm{t}=1$ minute, Dose $=1.0, \mathrm{r}=1 \mathrm{~cm}$ and $\mathrm{L}=600 \mathrm{~cm}$. Since the concentration profile has a strong dependence on $T_{D}$, these plots could be used to estimate the value of $T_{D}$ (and $\mathrm{T}_{\mathrm{F}}$ ) in the human if experimental measurements of the concentration profile along the small intestine for impermeable solutes were available. Unfortunately, no such measurements have been reported for humans or other large mammals (they have been made in rats [19]).

The experimental measurement in humans that can be used to estimate $T_{D}$ is the distribution of small intestinal transit times determined from the appearance of some nonpermeable label in the large intestine [20]. Figure 6 shows the DC cumulative amount entering the large intestine as a function of time (Equation (4)) for $\mathrm{T}_{\mathrm{D}}=2000$ (red), 1000

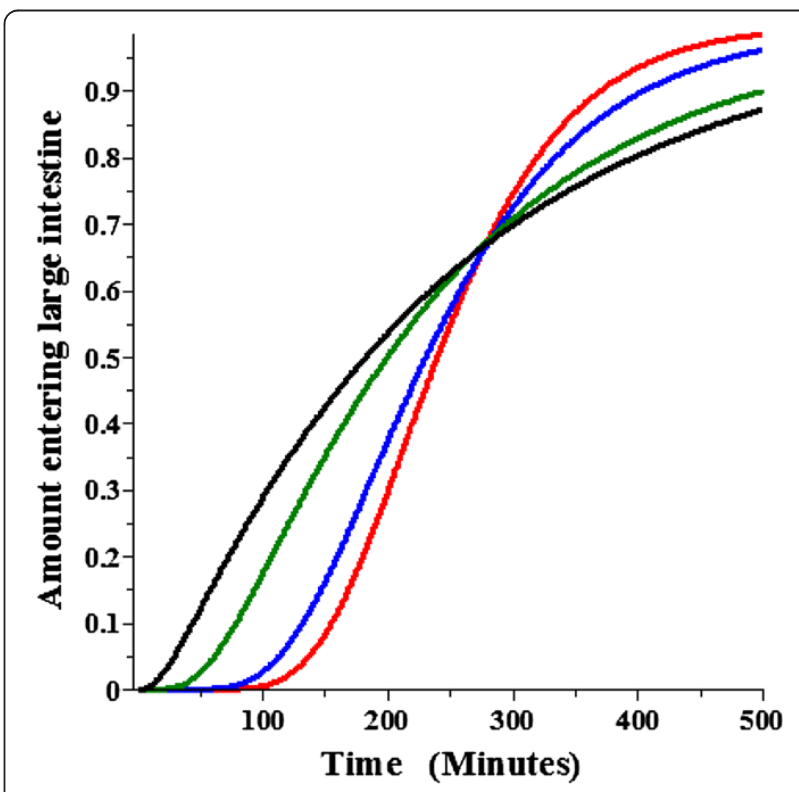

Figure 6 Diffusion convection small intestinal transit time. The diffusion convection amount leaving the small intestine and entering the large intestine as a function of time for an impermeable solute. Same conditions as for Figure 5. 
(blue), 200 (green) and 20 (black) minutes for the same conditions as in Figure 5. The shape of the curves can be roughly characterized by the time of first appearance of solute and the half time. Caride et. al. [21] reported the time of arrival (time at which a "sustained" increase in breath hydro-

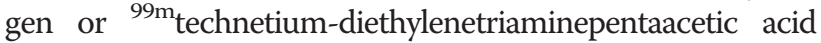
was first detected) of about 73 minutes. Based on an extensive literature review, Davis et. al. [22] found an average small intestinal half time of about 240 minutes. From Figure $6, \mathrm{a} \mathrm{T}_{\mathrm{D}}$ of about 200 minutes provides the best fit to these experimental measurements in humans.

In the next section, the DC model will be used to evaluate the accuracy of the AM model approximation. The plots in Figures 5 and 6 are for non-permeable solutes. Figure 7 shows a plot of the DC fraction absorbed versus the permeability $\left(10^{-4} \mathrm{~cm} / \mathrm{sec}\right)$ for $T_{D}=1000$ (blue) and 200 (green) minutes. It can be seen that for the high permeability solutes the fraction absorbed increases by about $5 \%$ as $\mathrm{T}_{\mathrm{D}}$ increases 5 fold (i.e. as the dispersion rate decreases). This produces a small dependence of the error in the AM absorption rate on $T_{D}$ (see below) which is quantitated in the next section.

\section{Comparison of DC and AM models - theoretical} evaluation of accuracy of AM model approximation

The procedure that will be used to measure the experimental permeability is to fit the AM absorption rate Equation (15) to the systemic absorption rate determined

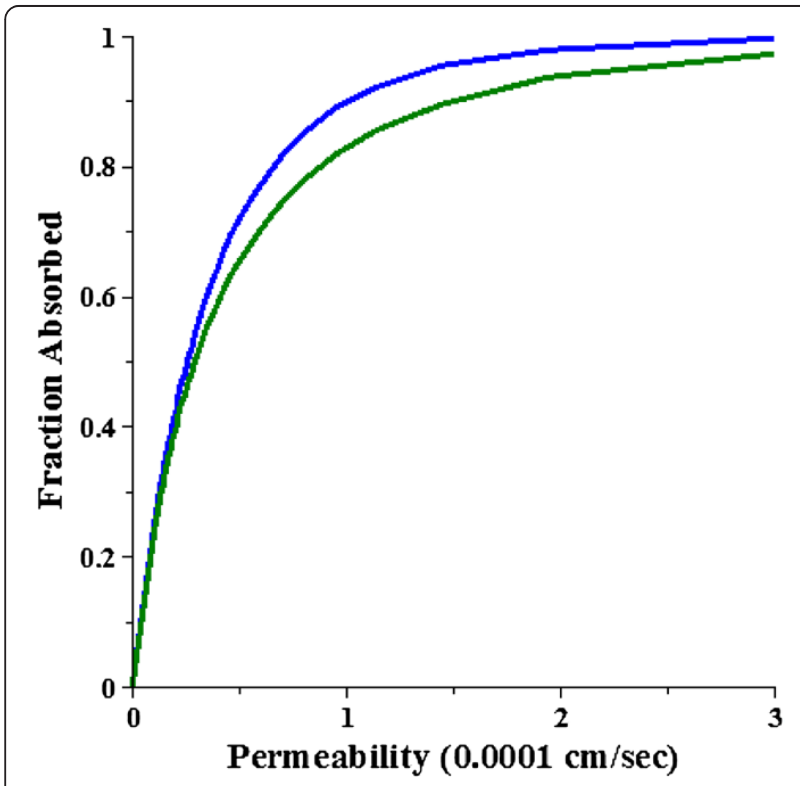

Figure 7 Permeability dependence of the diffusion convection intestinal absorption. The fractional absorption of the diffusion convection model as a function of the permeability in units of $10^{-4} \mathrm{~cm} / \mathrm{sec}$ for a dispersion time constant ( $T_{D}$ ) of 1000 (blue) or 200 minutes (green). The rest of the conditions are the same as in Figure 5. by deconvolution. The accuracy of this procedure will be theoretically tested here by fitting Equation 15 to the general DC model absorption rate and comparing the AM permeability to the permeability that is used to generate the $\mathrm{DC}$ absorption data. Figure $8 \mathrm{~A}$ and $\mathrm{B}$ compare the absorption rate as a function of time for the DC model (red) versus the best fit $\mathrm{AM}$ model (blue) for the case where the DC $\mathrm{T}_{\mathrm{D}}=200$ minutes and $\mathrm{T}_{\mathrm{F}}=240$ minutes $\left(\right.$ and $\mathrm{T}_{\mathrm{G}}=$
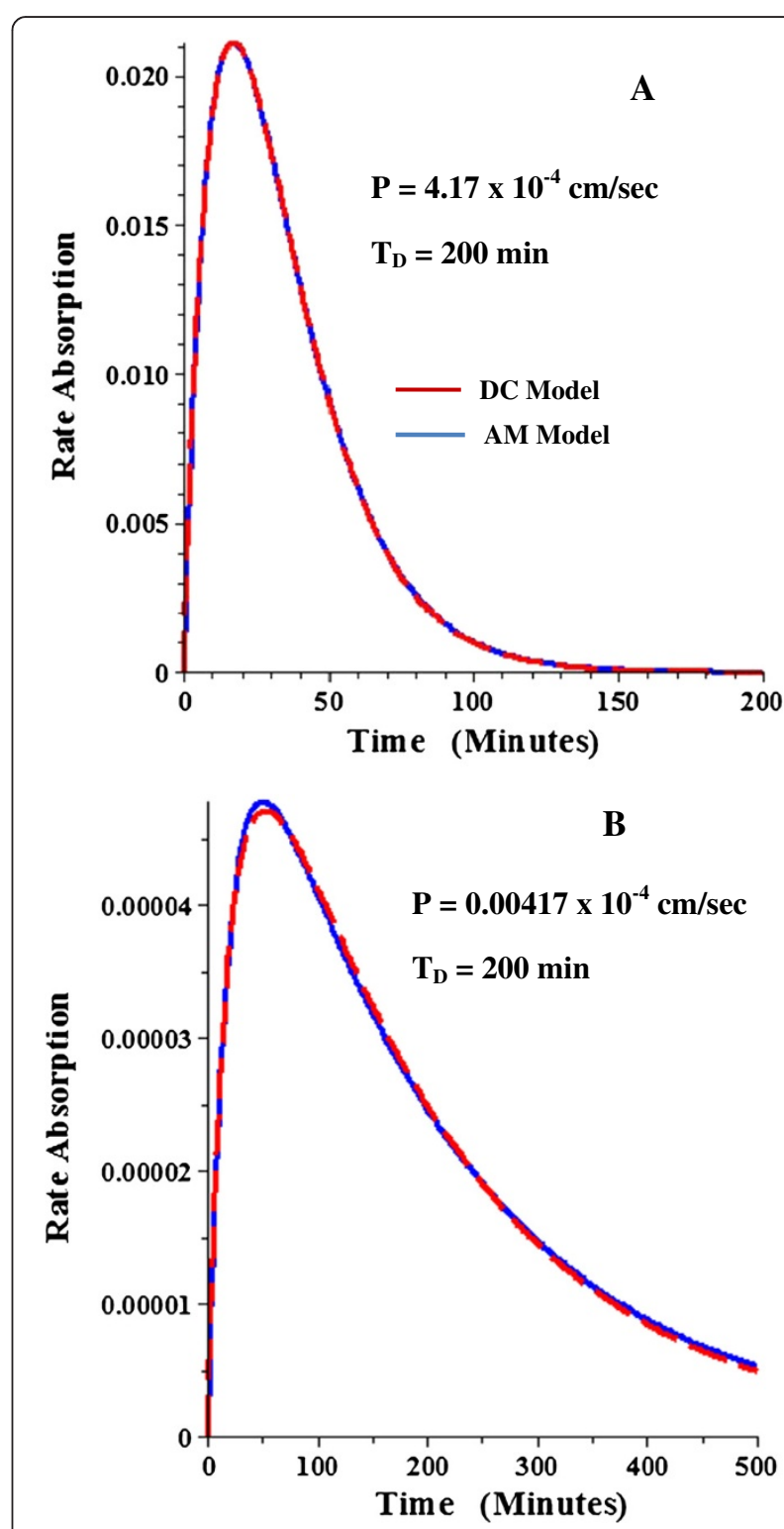

Figure 8 Comparison of intestinal absorption rate for DC and AM models with $T_{D}=\mathbf{2 0 0}$ minutes. The $D C$ model rate of absorption (red) was generated for a high permeability solute $(P=$ $4.17 \times 10^{-4} \mathrm{~cm} / \mathrm{sec}$, Figure $\left.8 \mathbf{A}\right)$ and a low permeability solute $(P=$ $0.00417 \times 10^{-4} \mathrm{~cm} / \mathrm{sec}$, Figure 8 B) with the rest of conditions the same as in Figure 5. Then the AM model parameters that provided the best fit to the DC model were determined and the AM absorption rate (blue) plotted. See Table 1 for tabulation of the AM parameters. 
15 min, $\mathrm{r}=1 \mathrm{~cm}, \mathrm{~L}=700 \mathrm{~cm}$ ). Figure $8 \mathrm{~A}$ shows that the AM model provides a nearly perfect fit to the DC absorption rate for the case of a relatively high permeability solute $\left(\mathrm{T}_{\mathrm{P}}=200 \mathrm{~min}\right.$, corresponding to $\left.\mathrm{P}=4.167 \times 10^{-4} \mathrm{~cm} / \mathrm{sec}\right)$. This is expected because only $1 \%$ of the solute passes from the small to large intestine for this high permeability and, as shown above, the AM and DC models are theoretically identical if all the solute is absorbed. More surprisingly, the DC and AM models are nearly identical (Figure $8 \mathrm{~B}$ ) even for solutes with a very low permeability $\left(\mathrm{P}=0.004167 \times 10^{-4} \mathrm{~cm} / \mathrm{sec}\right)$ where only $1 \%$ of the solute is absorbed. If the dispersion time constant $\left(\mathrm{T}_{\mathrm{D}}\right)$ is increased to 1000 minutes, the AM model provides a poorer approximation to the DC absorption rate for solutes with a low permeability (Figure 9B).

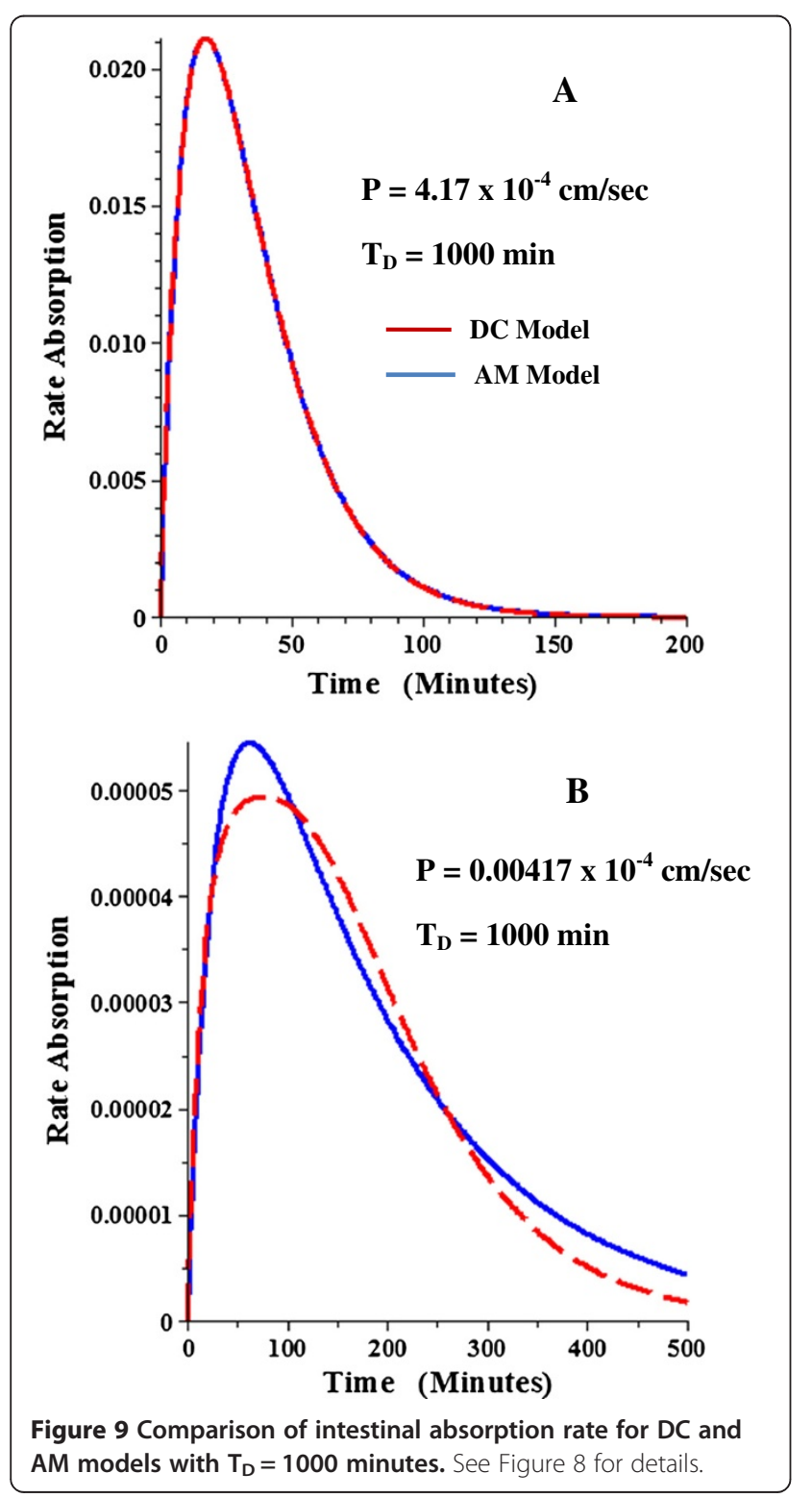

The quantitative comparison between the DC parameters used to generate the absorption rate and the AM parameters $\left(\mathrm{T}_{\mathrm{G}}, \mathrm{T}_{\mathrm{B}}\right.$, and $\left.\mathrm{F}_{\mathrm{A}}\right)$ that provide an optimal fit to this DC absorption rate are listed in Table 1 for a large range of values of the DC parameters. For $\mathrm{T}_{\mathrm{D}}=200 \mathrm{~min}$, the AM permeability is within $20 \%$ of the DC permeability for a thousand fold permeability range (total absorption varying from 1\% to 99\%). For $\mathrm{T}_{\mathrm{D}}=1000 \mathrm{~min}$, the AM permeability can reach values $60 \%$ greater than the DC permeability for very low permeability solutes. Since the normal human $T_{D}$ is about 200 minutes (Results, previous section), these results show that the AM model provides a good approximation to the exact $\mathrm{DC}$ model for a wide range of permeabilities.

\section{AM model estimates of the human intestinal permeability of 90 solutes}

The Excel Table in the Additional file 1: Table 2 lists the values of the intestinal permeability for 90 solutes determined using the AM model and deconvolution. As discussed in the Methods there are two time constants in the AM model. For most of the solutes in this table, an oral solution was administered to fasting subjects so that the value of $\mathrm{T}$ in the range of 10 to 20 minutes can be assumed to be $T_{G}$. For the few solutes in the table in which a tablet or capsule was administered, the solute had such a low permeability that it was clear that the longer $\mathrm{T}$ must correspond to $\mathrm{T}_{\mathrm{P}}$.

In order to determine the permeability it is essential to relate the rate of solute absorption into the systemic circulation determined by deconvolution to the rate of intestinal absorption and this requires estimates of the liver and intestinal first pass extraction (Equation (15)). The liver extraction was determined from the estimated liver blood flow and the liver clearance (Equation (16)). The liver clearance is equal to the total systemic clearance (determined from the IV input blood data) corrected for the fractional renal clearance. These values are listed in Additional file 1: Table 2 for each solute. The value for the liver flow is just an estimate and for some drugs, e.g. $\beta$-blockers, the value is reduced. The intestinal extraction is more uncertain. Although certain drug classes are known to have significant intestinal metabolism, there is no quantitative data available in humans [23]. In Additional file 1: Table 2 the column labeled "Est Fraction Absorbed" represents the final estimate taking account of the best guess for intestinal extraction.

Three representative examples of AM model deconvolution calculations will be described in detail. Acetaminophen is the classic example of a high permeability drug. Its intestinal absorption rate is usually assumed to be so fast that its absorption rate is a measure of the rate limiting gastric emptying [24-26]. The deconvolution 
Table 1 Comparison of "averaged" (AM) and dispersion convection (DC) absorption rates

\begin{tabular}{|c|c|c|c|c|c|c|}
\hline \multicolumn{4}{|c|}{ DC Model } & \multicolumn{3}{|c|}{ AM Model } \\
\hline$P_{D C}\left(10^{-4} \mathrm{~cm} / \mathrm{sec}\right)$ & $T_{D}(\min )$ & $T_{G}(\min )$ & Fr. Absorb & $\mathrm{P}_{\mathrm{AM}}\left(10^{-4} \mathrm{~cm} / \mathrm{sec}\right)$ & $T_{G}(\min )$ & Fr. Absorb \\
\hline 4.167 & 200 & 15 & .987 & 4.77 & 17.2 & .989 \\
\hline 0.4167 & 200 & 15 & 0.600 & 0.493 & 18.56 & 0.604 \\
\hline 0.04167 & 200 & 15 & 0.109 & 0.0514 & 19.76 & 0.111 \\
\hline 0.004167 & 200 & 15 & 0.0119 & 0.00517 & 19.9 & .012 \\
\hline 4.167 & 1000 & 15 & 0.999 & 4.167 & 15 & 0.999 \\
\hline 0.4167 & 1000 & 15 & 0.658 & 0.522 & 20.8 & 0.690 \\
\hline 0.04167 & 1000 & 15 & 0.111 & 0.0645 & 29 & 0.121 \\
\hline 0.004167 & 1000 & 15 & 0.0119 & 0.0067 & 30 & 0.0129 \\
\hline 4.167 & 200 & 60 & 0.997 & 4.155 & 60.0 & 0.997 \\
\hline 0.04167 & 200 & 60 & 0.109 & 0.062 & 86 & 0.107 \\
\hline 4.167 & 1000 & 60 & 0.999 & 4.167 & 60.0 & 0.999 \\
\hline 0.04167 & 1000 & 60 & 0.112 & 0.0879 & 114.5 & 0.121 \\
\hline
\end{tabular}

The theoretical time dependent absorption rate was generated for the $D C$ parameters listed in the table $\left(P_{D C}=\right.$ permeability, $T_{D}$ and $T_{G}=$ the dispersion and gastric emptying time constants). For all results, $T_{F}=240 \mathrm{~min}, r=1 \mathrm{~cm}, \mathrm{~L}=700 \mathrm{~cm}$. The DC "Fr. Absorb" is the resultant cumulative fraction absorbed. The AM parameters (permeability $\left(\mathrm{P}_{\mathrm{AM}}\right), \mathrm{T}_{\mathrm{G}}$ and Fr. Absorb) were then adjusted to obtain the optimum fit to the DC absorption rate, similar to the procedure used to determine the experimental human small intestinal permeability by deconvolution.

results shown in Figure 1 are based on the data of Ameer et. al. [27] for a $650 \mathrm{mg}$ IV and oral (elixir) dose (data for one "representative" subject). Figure 1A shows the 2 exponential response function fit to the IV input data. Figure $1 \mathrm{~B}$ compares the AM model prediction of the blood concentration with the experimental data for the oral dose, and Figure $1 \mathrm{C}$ shows the cumulative predicted absorption rate. The AM parameters are $\mathrm{M}=$ $545 \mathrm{mg}$, and the two time constants are 2 and $14 \mathrm{mi}-$ nutes. As discussed above, it is assumed that the time constant closest to 15 minutes is $\mathrm{T}_{\mathrm{G}}$, and therefore $\mathrm{T}_{\mathrm{P}}=$ 2 minutes. Correcting $M$ for the liver extraction (Equation (16)) yields a fraction absorbed of 1.07 ; i.e. $100 \%$ absorption which is expected given the fact that the amount absorbed reaches its maximum by 50 minutes (Figure $1 \mathrm{C}$ ), well before one would expect a significant amount to pass into the large intestine. From Equation (13), assuming an $r$ of $1 \mathrm{~cm}$, the acetaminophen permeability $\mathrm{P}_{\mathrm{M}}$ is $41.7 \times 10^{-4}$ $\mathrm{cm} / \mathrm{sec}$. There are two other published sets of acetaminophen data that can be used to estimate the permeability by deconvolution. The data of Divoll et. al. [28] (650 mg oral elixir data for representative "elderly" subject) has a $\mathrm{P}_{M}$ of $54 \times 10^{-4}$ and that of Eandi et. al. [29] (averaged data $(\mathrm{n}=9)$ for $1 \mathrm{gm}$ oral "drops") has a $\mathrm{P}_{\mathrm{M}}$ of $12.6 \times 10^{-4} \mathrm{~cm} / \mathrm{sec}$.

Risedronate is a pyridinyl bisphosphonate with a very low intestinal permeability (bioavailability $<1 \%$ ). Despite this low permeability, the plasma pharmacokinetics described by Mitchell et. al. [30] after an oral (30 mg solution) and IV infusion ( $0.3 \mathrm{mg}$ ) can be used to determine the time course of intestinal absorption by deconvolution (Figure 2). The AM model provides an excellent fit to the oral plasma data (Figure 2B) with $\mathrm{M}=220 \mathrm{mg}$
( $=0.73 \%$ of $30 \mathrm{mg}$ oral dose), $\mathrm{T}_{\mathrm{G}}=14$ and $\mathrm{T}_{\mathrm{P}}=79.4 \mathrm{mi}-$ nutes. Using the fraction absorbed of 0.0073 in Equation (13), $\mathrm{P}_{\mathrm{M}}=0.008 \times 10^{-4} \mathrm{~cm} / \mathrm{sec}$. (Since risedronate is not metabolized [30], there is no significant first pass metabolism.) The absorption is complete by 300 minutes (Figure 2C) presumably because this is the time required for complete emptying into the large intestine. This result also suggests that there is no significant absorption from the large intestine.

First pass intestinal extraction cannot be quantitatively measured in humans. In Additional file 1: Table 2 the assumed intestinal metabolism is indicated by the difference between the estimated total absorption (the column labeled "Est Fract Abs Small Intestine") and the systemic absorption corrected for the liver extraction (column labeled "Fract Abs Corrected for Liver Clearance"). For example, cimetidine has a highly variable bioavailability of about $65 \%$ that has been attributed to either low intestinal permeability or intestinal metabolism [31]. The AM model provides a good fit (Figure 3A) to the blood concentration following a $300 \mathrm{mg}$ oral solution dose [32]. The $A M$ parameters are $M=175 \mathrm{mg}, \mathrm{T}_{\mathrm{G}}=$ 10 and $\mathrm{T}_{\mathrm{P}}=25$ minutes. Correcting for liver extraction raises the amount absorbed to $203 \mathrm{mg}$ (68\% of the oral dose). From the AM model time course of the amount absorbed (Figure $3 \mathrm{~B}$ ) it can be seen that the absorption is complete by about 100 minutes. This is short compared to the presumed small intestinal transit time of about $300 \mathrm{mi}$ nutes, suggesting that permeability is not limiting and that intestinal metabolism is responsible for the incomplete absorption. This approach of assuming that permeability is not rate limiting if the absorption is completed in, e.g., 
150 minutes can be used as a general criteria for determining if intestinal metabolism is important. (Note: this criteria is not applicable to acidic drugs, see Discussion). The extreme example of this for the drugs in Additional file 1: Table 2 is domperidone for which as much as $63 \%$ may be cleared by intestinal metabolism [33]. Cimetidine and domperidone are exceptions and for most of the drugs in Additional file 1: Table 2 intestinal metabolism is not significant.

\section{Discussion}

As shown above (Results, Comparison of DC and AM models), the 3 parameter averaged model (AM) provides a good estimate of the small intestinal permeability if the following 2 conditions are met: 1) gastric emptying can be described by a single exponential process; and 2) the assumptions underlying the diffusion-convection (DC) model are valid. In addition, to convert the $A M$ value of $T_{P}$ to an absolute permeability requires an assumption about the small intestinal radius (r, Equation (13), assumed = $1 \mathrm{~cm}$ ). The analysis listed in the Additional file 1: "Table 2" is limited primarily to drugs that were administered as oral solutions to fasting subjects, conditions for which the exponential emptying should be a good approximation [14]. The basic assumption of the DC model is that the small intestine can be described by a uniform volume cylinder with convective flow into each segment exactly balanced by flow out, combined with a mixing dispersion term, with all properties uniform for its entire length. This is, at best, an approximate description of the small intestine. Little is known about the details of small intestinal volume, mixing and dispersion in a fasting human subject that has swallowed the small volume of water (about $200 \mathrm{ml}$ ) that is usually administered in these oral solution dose studies.

Probably the most severe limitation of the DC model is the assumption that the parameters do not vary over the length of the intestine. The luminal $\mathrm{pH}$ definitely varies with position and, since the permeability of weak acids and bases depends critically on $\mathrm{pH}$, this implies that their permeability will also vary with position. There have been a number of measurements of the $\mathrm{pH}$ position dependence of the human intestine. In a review of the older literature, Gray and Dressman [34] reported $\mathrm{pH}$ values of 4.9 in proximal duodenum, 5.3 in terminal duodenum, 4.4-6.5 in proximal jejunum, 6.6 in mid and terminal jejunum and varying from 6.5 in proximal ileum to 7.4 in terminal ileum. Using in situ $\mathrm{pH}$ microelectrodes Ovesen et. al. [35] simultaneously measured a fasting $\mathrm{pH}$ of 2.05 in stomach, 3.03 in duodenal bulb, 4.9 in mid duodenum and 4.92 in proximal jejunum. Using radiotelemetry capsules swallowed "with a small quantity of water", Evans et. al. [36] reported pH values of 6.63 in jejunum, 7.41 in mid small bowel, 7.49 in ileum and from 6.37 to 7.04 in colon. Using the "smart pill", Lalezari [37] recently reported $\mathrm{pH}$ values varying from $5.6,6.2,6.68,6.9$ for proximal to terminal small intestinal quartiles. Thus, the small intestinal $\mathrm{pH}$ can be assumed to start at about 4.4 in an initial short segment of the duodenum, increasing to 5.4 in the first part of the jejunum, to 6.4 in mid intestine and to 7.4 in the terminal ileum.

The results in Additional file 1: Table 2 will be discussed in terms of the classical $\mathrm{pH}$ partition assumption that the permeability is proportional to the concentration of the neutral moiety, using the octanol/water partition $(\log \mathrm{D})$ as representative of the epithelial membrane partition and the pKa to estimate the neutral concentration [38]. Since the small intestinal $\mathrm{pH}$ varies from about 4.4 to 7.4, this $\mathrm{pH}$ partition hypothesis implies that the intestinal permeability can vary by as much as 1000 fold over its entire length. Although more complicated approaches that combine $\log \mathrm{D}$ with estimates of polar surface area and hydrogen bond donors can improve permeability estimates [39], $\log \mathrm{D}$ captures the main features and will be focused on here. It is hoped that the data set in Additional file 1: Table 2 will be used in future evaluations of these advanced models.

Since the permeability of the 18 uncharged solutes in Additional file 1: Table 2 should not be affected by this $\mathrm{pH}$ heterogeneity, one would predict that the AM permeability for these solutes should be a good approximation to the true permeability. Figure 10 shows a plot of the $\log \mathrm{D}$ versus the $\log$ of the permeability $(\mathrm{cm} / \mathrm{sec})$. The 5 colored points indicate solutes for which there is strong evidence of protein mediated transport. The 3 green points have P-glycloprotein mediated efflux (digoxin and $\beta$-methyl digoxon [40] and colchicine [41]) which should reduce their permeability. The blue point is lamivudine which is a substrate for the organic cation transporters [42] and the red point is xylose which has a carrier mediated transport (probably the glucose transport system) [43-45], both of which will increase the "permeability". The black line is the least squares regression fit to the black (non-protein mediated) points. There is only a weak correlation between permeability and $\log$ D. Presumably other factors besides simple octanol partition are important. The 4 points with the highest permeability (caffeine, acetaminophen, antipyrine and cotinine) are all low molecular weight $(<200)$ solutes. The 2 points with $\log \mathrm{D}<-1.5$ (acyclovir and ganciclovir) may have significant paracellular transport.

One would predict that the small intestinal $\mathrm{pH}$ heterogeneity should significantly influence the apparent AM "permeability" of the basic solutes listed in Additional file 1: Table 2. Since the basic solutes have a higher uncharged concentration at the higher $\mathrm{pH}$, they will tend to be absorbed in the terminal small intestine - delaying 


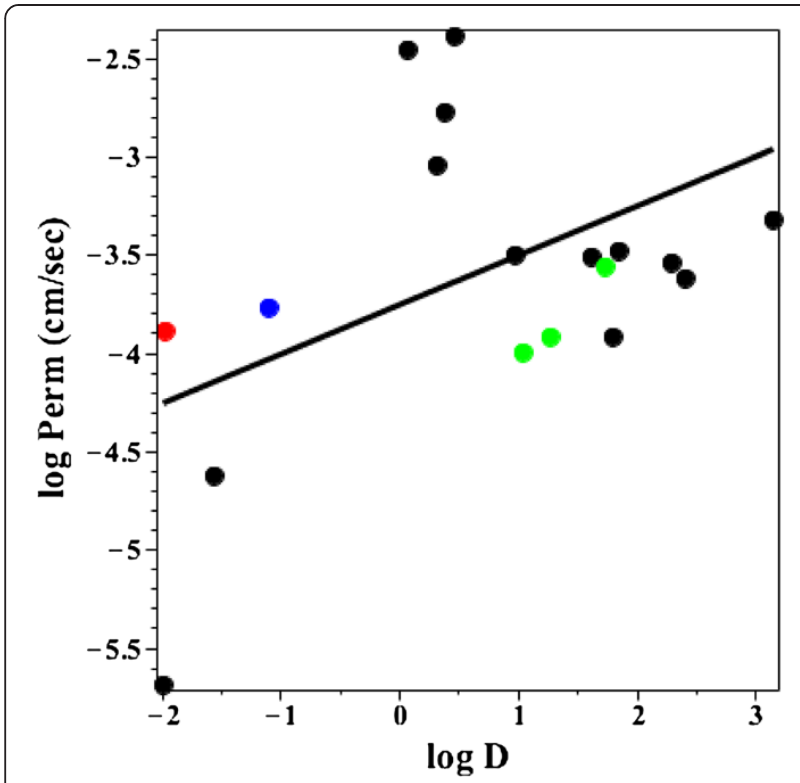

Figure 10 Permeability versus octanol partition for neutral solutes. Plot of the log of the permeability $(\mathrm{cm} / \mathrm{sec})$ versus the log of the octanol/water partition ( $\log \mathrm{D})$ for the neutral solutes in Additional file 1: Table 2. The colored points indicate solutes which may have protein mediated transport: Red $=$ xylose (glucose transport system); Green = digoxin, $\beta$-methyl digoxin and colchicine (P-glycloprotein mediated efflux); Blue = lamivudine (organic cation transporter). The solid line is the linear regression fit to the black points.

their absorption and decreasing the calculated permeability. This delay should have a complicated dependence on $\log \mathrm{D}$. Solutes with a relatively high $\log \mathrm{D}$ at $\mathrm{pH} 6.5$ will be absorbed in the first part of the intestine and have a correspondingly higher apparent permeability then solutes with a low $\log \mathrm{D}$ whose absorption will be delayed until they reach the $\mathrm{pH}$ of 7.4 in the ileum. Figure 11 shows a plot of $\log \mathrm{D}$ versus $\log$ permeability for the basic solutes in Additional file 1: Table 2 for a log $\mathrm{D}$ determined at $\mathrm{pH}$ 7.4 (Figure 11A), $\mathrm{pH}$ 6.4 (Figure 11B) and $\mathrm{pH}$ 5.4 (Figure 11C) using Equation (20) to convert the $\log \mathrm{D}$ to the different $\mathrm{pHs}$. The orange point is midodrine which is a known substrate for the peptide transport system [46]. The solid line is the linear regression fit to the black points and the dashed line is the regression for the neutral solutes (Figure 10). The pH 6.4 plot provides the best fit to the neutral solute permeability data (which should not be $\mathrm{pH}$ dependent), suggesting that $\mathrm{pH} 6.4$ is the best average approximation for basic solutes. This is consistent with the current recommendation to use a $\mathrm{pH}$ of 6.8 for studies of "simulated" intestinal fluid [34]. As predicted, the AM permeability of the basic solutes with low $\log \mathrm{D}$ at $\mathrm{pH} 6.4$ or 7.4 is less than that of the neutral solutes (dashed line) because their absorption should be delayed until they reach the ileum. This comparison between the neutral and basic solutes is only suggestive because of the small number of neutral solutes in Additional file 1: Table 2 and their poor correlation with $\log \mathrm{D}$ (Figure 10).

The opposite effect should occur for the acidic solutes which should be absorbed in the proximal (acidic) section of the intestine. The classic example is aspirin, which has a pKa of 3.49 and a $\log \mathrm{D}$ of about -1.8 (average from LOGKOW) at pH 7.4. From the plots in Figures 10 or 11, one would predict that a solute with this $\log \mathrm{D}$ should have a low permeability of about $0.4 \times 10^{-4} \mathrm{~cm} / \mathrm{sec}$, about 25 times smaller than the experimental AM aspirin permeabilities (Additional file 1: Table 2) of $6.69 \times$ $10-4 \mathrm{~cm} / \mathrm{sec}$ (Rowland et al. [47] for one subject) or $20.8 \times 10^{-4} \mathrm{~cm} / \mathrm{sec}$ (Bochner et al. [48], average of 6 subjects). The explanation of this high permeability has been controversial. Hogben et al. [49] used this rapid absorption of aspirin to infer that there must be a $\mathrm{pH}$ of about 5.3 at the luminal surface of the epithelial cell maintained by some unknown mechanism combined with a large unstirred luminal fluid layer. However, the recognition that the unstirred layer in humans is only about $35 \mu \mathrm{m}$ [50] makes this idea untenable and direct measurements in guinea pig jejunum do not find evidence for this acidic mircroclimate [51]. An alternative explanation is that the salicylates are transported by a monocarboxylic acid carrier system [52,53]. However, Takagi et al. [54] suggested this result is an artifact and that pure phospholipid liposomes show the same apparent "carrier" behavior. The most likely explanation is simply that aspirin is absorbed in the duodenum and proximal jejunum where the $\mathrm{pH}$ varies from 4.4 to 5.4. At a pH of 5.4, the $\log \mathrm{D}$ of aspirin is about 0.19 (Equation (20)) and small neutral solutes with this $\log \mathrm{D}$ (e.g. caffeine, see Figure 10) have high AM permeabilities, equal to or greater than are observed for aspirin. The aspirin permeability at $\mathrm{pH} 5.4$ is presumably high enough that it can be nearly completely absorbed in this short proximal region.

A dramatic illustration of the effect of this $\mathrm{pH}$ heterogeneity on the absorption of weak acids is provided by acetylcysteine which has a pKa of 3.25 and a very low $\log \mathrm{D}$ of -2.5 at $\mathrm{pH} 7.4$ with a corresponding $\log \mathrm{D}$ of -1.5 at $\mathrm{pH} 6.4$ and -0.6 at $\mathrm{pH} 5.4$. The AM fit to the blood concentration following the oral dose and the time course of the intestinal absorption is shown in Figure 4. Even though the permeability time constant $T_{P}$ is very fast (6.95 minutes), only about $12 \%$ of the $3676 \mu \mathrm{m}$ oral dose is absorbed and the absorption stops after about 50 minutes (Figure 4B). This suggests that the absorption occurred only in the low $\mathrm{pH}$ proximal small intestine and this region was cleared by about 50 minutes after $12 \%$ was absorbed and that there was no significant absorption in the rest of the intestine. 


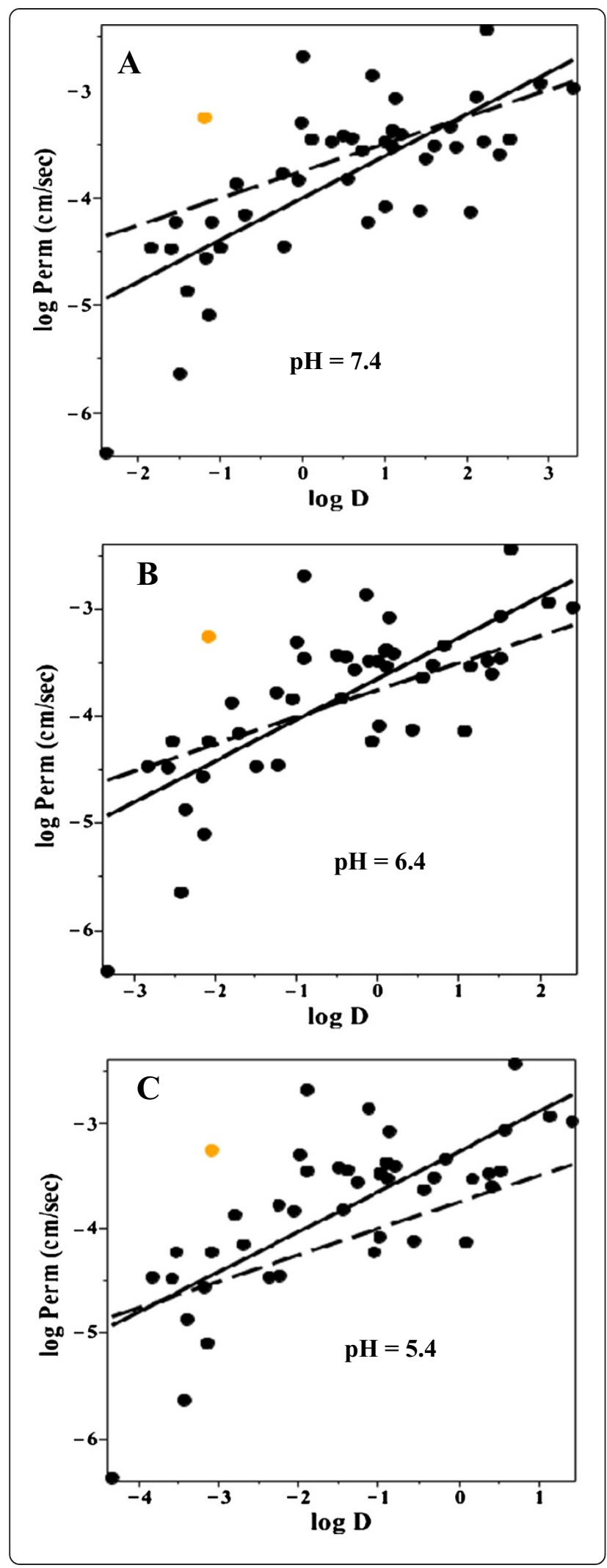

Figure 11 Permeability versus octanol partition for basic solutes. Plot of the log of the permeability $(\mathrm{cm} / \mathrm{sec})$ versus the log of the octanol/water partition (log D) for the basic solutes in Additional file 1: Table 2. The log D was determined at $\mathrm{pH}=7.4$ (Figure 11A), 6.4 (Figure 11B) and 5.4 (Figure 11C). The solid line is the linear regression fit to the black points and the dashed line is the linear regression fit to the neutral solutes (Figure 10). The orange point is midodrine which is a substrate for the peptide transport system.

Figure 12 shows a plot of the log permeability versus the $\log \mathrm{D}$ at $\mathrm{pH}$ 7.4 (Figure 12A), 6.4 (Figure 12B) and 5.4 (Figure 12C) for the 10 acidic solutes in Additional file 1: Table 2. The solid line is the linear regression fit to the black points and the dashed line is the regression for the neutral solutes (Figure 10). There is no significant correlation between $\log \mathrm{D}$ and the permeability. This is probably because most of these solutes are relatively rapidly and nearly completely absorbed in the proximal intestine and the $\log \mathrm{D}$ varies over a smaller range than the basic solutes (Figure 11).

Figure 13 shows a plot of the log permeability versus the $\log \mathrm{D}$ for the 7 solutes in Additional file 1: Table 2 that are charged over the entire $\mathrm{pH}$ range 5.4 to 7.4. The 2 green points indicate solutes that may be substrates for the peptide transport system. All the solutes have low permeabilities that are less than are predicted by the neutral solute plot (dashed line). These solutes are probably absorbed primarily by paracellular transport.

The best currently available measurements of human small intestinal permeability are the single-pass jejunal perfusion results of Lennernas and colleagues. Currently, they have published the jejunal permeability for 28 drugs [18]. Figure 14 shows a log-log plot of the AM versus the perfused jejnunal permeability for the 8 drugs that were studied by both methods. The dashed line is the line of identity. The black and red points are weak bases and acids, respectively, and the green point is the uncharged solute antipyrine. It can be seen that for most solutes the AM permeability is in good absolute agreement with the direct perfusion permeability - a surprising result considering the marked differences in experimental approaches and assumptions for the two methods. The major exception is the weak acid furosemide (red point) whose AM permeability $\left(1.54 \times 10^{-4} \mathrm{~cm} / \mathrm{sec}\right)$ is 30 times greater than the perfusion permeability, presumably because furosemide is absorbed primarily in the proximal jejunum that has a $\mathrm{pH}$ significantly more acid than the $\mathrm{pH}$ of 6.5 used in the perfusion studies.

One can use the AM permeability of the highest permeability solutes to estimate a lower bound for the unstirred aqueous layer. For the passively absorbed high lipid solubility drugs, the permeability (P) should be approximately equal to that of the total fluid 


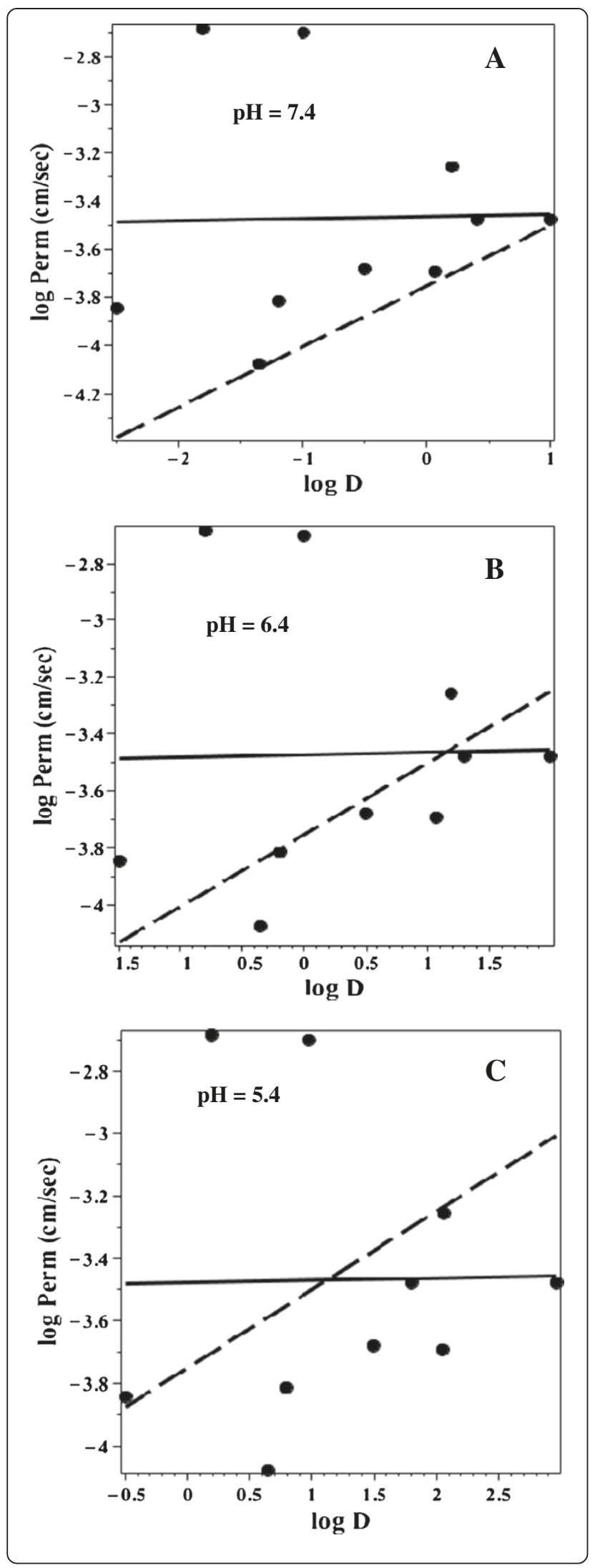

Figure 12 Permeability versus octanol partition for acidic solutes. Plot of the log of the permeability $(\mathrm{cm} / \mathrm{sec})$ versus the log of the octanol/water partition ( $\log \mathrm{D})$ for the acidic solutes in Additional file 1: Table 2. The $\log \mathrm{D}$ was determined at $\mathrm{pH}=7.4$ (Figure 12A), 6.4 (Figure 12B) and 5.4 (Figure 12C). The solid line is the linear regression fit to the black points and the dashed line is the linear regression fit to the neutral solutes (Figure 10).

layer separating the intestinal capillaries from the well stirred lumen:

$$
P=D_{U S} / L_{U S}
$$

where $\mathrm{L}_{\mathrm{US}}$ is the thickness and $\mathrm{D}_{\mathrm{US}}$ is the average diffusion coefficient for this fluid layer. The small uncharged solutes (e.g. caffeine, acetaminophen and antipyrine) have the highest AM permeabilities of about $20 \times 10^{-4} \mathrm{~cm} / \mathrm{sec}$ (Additional file 1: Table 2). Assuming a D of $9.1 \times 10^{-6} \mathrm{~cm}^{2} /$ sec for, e.g., antipyrine in water at $37^{\circ} \mathrm{C}$ [55], $\mathrm{L}=45 \mu \mathrm{m}$. Since the epithelial cell thickness is about $25 \mu \mathrm{m}$ [56], this corresponds to an unstirred luminal layer of only about $20 \mu \mathrm{m}$, similar to the value of $35 \mu \mathrm{m}$ found by Levitt et al. [50] for human jejunum. This AM antipyrine permeability value is about 3 times larger than the value found by Fagerholm and Lennernas [55] at the highest rates of jejunal perfusion. The perfusion at a pressure of about $20 \mathrm{~mm} \mathrm{Hg}$ [57] produces an unphysiological distended

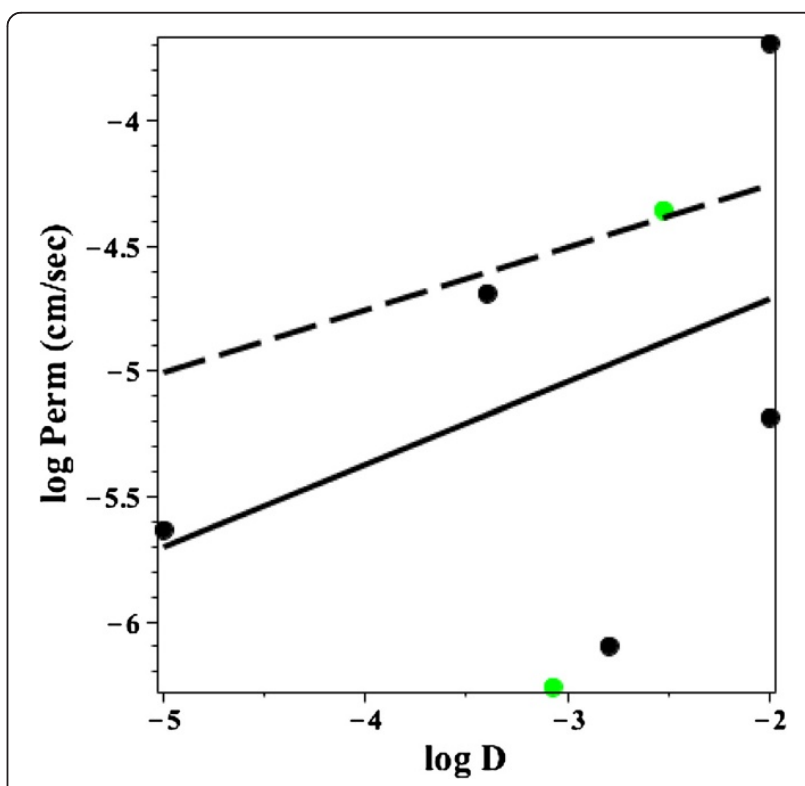

Figure 13 Permeability versus octanol partition for charged solutes. Plot of the log of the permeability $(\mathrm{cm} / \mathrm{sec})$ versus the log of the octanol/water partition (log D) for the charged solutes in Additional file 1: Table 2 . The solid line is the linear regression fit to the black points and the dashed line is the linear regression fit to the neutral solutes (Figure 10). The green points are cefixime and aztreonam which are substrate for the P-glycloprotein mediated efflux system. 


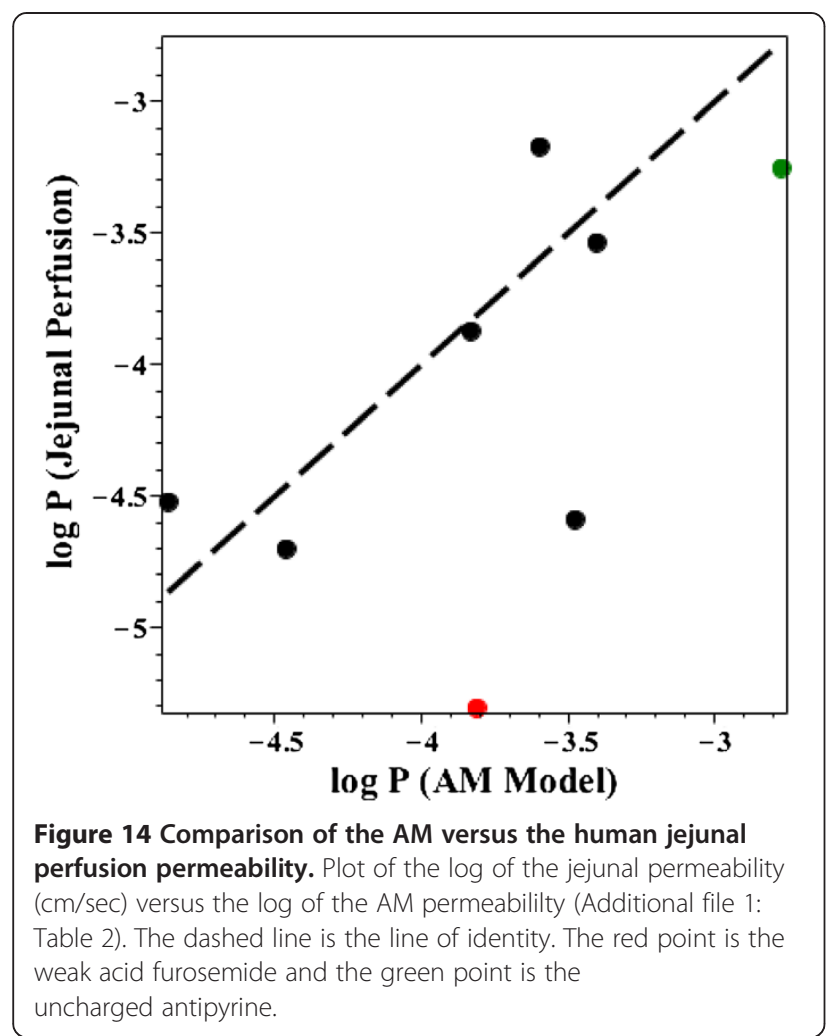

jejunum (radius of $1.61 \mathrm{~cm}$ ) [58] and one might expect greater unstirred layers than during the nearly fasting conditions used for the AM studies.

The standard procedure for screening for the intestinal permeability of drugs is the Caco-2 cell culture system. Comparison of the AM permeability with the Caco-2 permeability is inexact because of the variety of techniques that have been used for reported Caco- 2 values, with results differing by as much as 10 fold between different labs [1]. Larregieu and Benet [59] recently reviewed some of the problems in using Caco-2 as a surrogate for human permeability measurements. Thomas et al. [60] recently published a compilation of results for 120 drugs determined in their lab by the same method and these values were compared with the AM values for the drugs studied by both methods (Additional file 1: Table 2). In addition, Additional file 1: Table 2 was filled in with Caco-2 results from other labs. When more than one value was available, usually the larger permeability was used. Figure 15 shows a log-log plot of the AM versus Caco-2 permeability. The solid line is the linear regression fit. At the high permeability end of the regression, the AM permeability is about 40 times greater than the Caco-2 permeability. This is consistent with a Caco-2 unstirred layer that varies, depending on the stirring rate, from 564 to $2500 \mu \mathrm{m}$ [61], which is 12 to 55 times

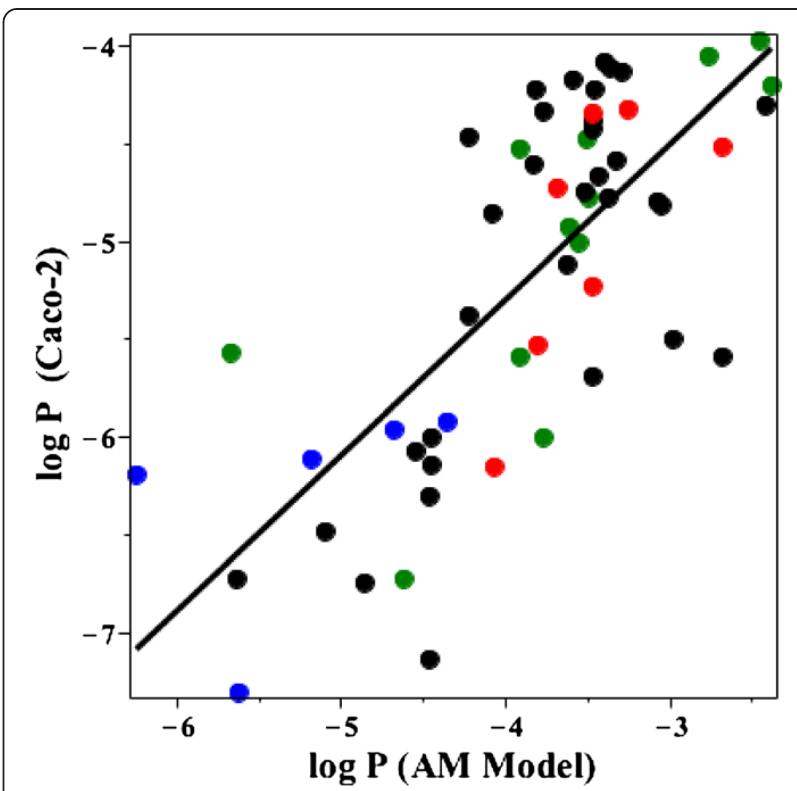

Figure 15 Comparison of the AM versus the Caco-2 permeability. Plot of the log Caco-2 permeability ( $\mathrm{cm} / \mathrm{sec}$ ) versus the log of the AM permeability (Additional file 1: Table 2). The points are colored on the basis of their charge state: Black = basic, Red = acidic, Green = uncharged, Blue = charged. The solid line is the linear regression fit to all the points.

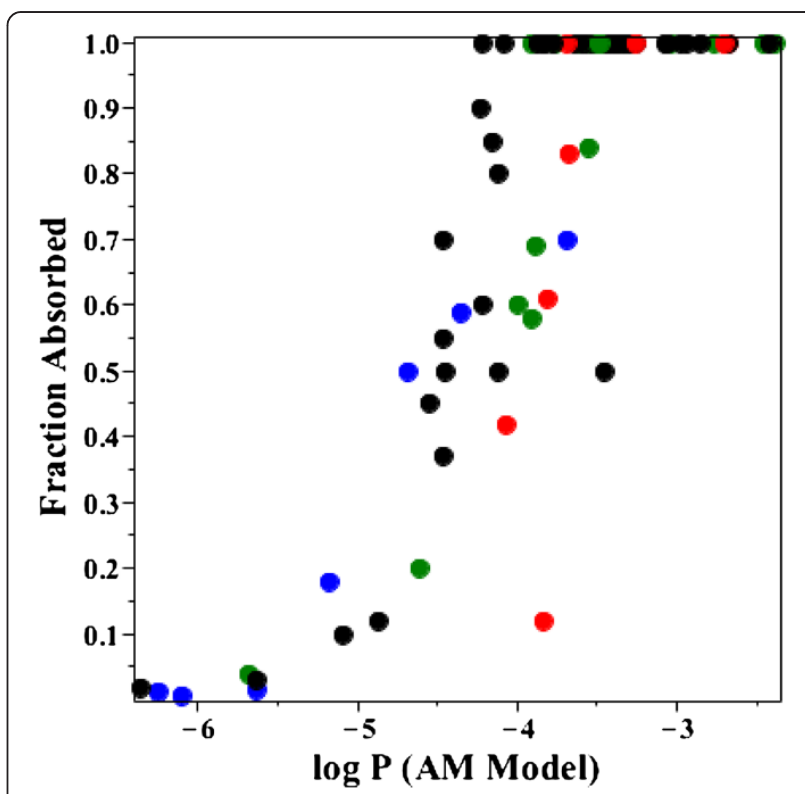

Figure 16 AM fraction absorbed versus AM permeability. Plot of the AM fraction absorbed versus the log of the AM permeability $(\mathrm{cm} / \mathrm{sec})$. The points are colored on the basis of their charge state: Black $=$ basic, Red $=$ acidic, Green $=$ uncharged, Blue $=$ charged . 
greater than the AM value. At the low permeability end where the unstirred layer is not limiting, the AM permeability is 6.8 times greater than the Caco-2 permeability.

As discussed in the Background section, the standard approach for evaluating QSAR predictions of intestinal drug permeability is to use the human fraction absorbed as a surrogate for the permeability. Although the limitations of this approach are well recognized [1], it is the only available correlate of absorption for most drugs. The plot of the fraction absorbed versus the log of the AM permeability for the drugs in Additional file 1: Table 2 (Figure 16) dramatically illustrates this limitation. For values of the AM P greater than about $10^{-4} \mathrm{~cm} / \mathrm{sec}$, the drugs are $100 \%$ absorbed and, for P less than about $10^{-5}$, absorption drops to $10 \%$ or less. Thus, although the permeability varies over a 10,000 fold range, the fraction absorbed varies from 0.1 to 1 over just a 10 fold permeability range. Although the fraction absorbed is the clinically most important prediction, it would clearly be useful to be able predict the permeability over a wider range. The data in Additional file 1: Table 2 should provide a useful benchmark for QSAR analysis.

\section{Conclusions}

The "averaged model" (AM) model accurately describes intestinal absorption if the assumptions of the diffusion convection (DC) model are satisfied. This new simple 3 parameter function (Equation (15)) can be used to determine by deconvolution the human intestinal permeability during the normal human drug absorption process. The AM permeability is similar to the values measured using direct jejunal perfusion. Its main limitation results from the heterogeneity in the small intestinal permeability of weak acids and bases produced by the variation in intestinal $\mathrm{pH}$. Weak acids will tend to be absorbed in the proximal intestine and weak bases in the terminal intestine and this will be represented in the "permeability" determined by this method. The permeability data for the 90 drugs described in the Additional file 1: "Table 2" provides a large data base that should be useful in drug development and QSAR analysis.

\section{Additional file}

Additional file 1: Table 2. Summary of averaged model (AM) deconvolution analysis of human intestinal absorption. Tabulated summary of all the permeability data used in the paper "Quantitation of small intestinal permeability during normal human drug absorption", D. G. Levitt.

\section{Abbreviations}

AM: Averaged model; DC: Diffusion convection model; D: Dispersion coefficient; Dus: average unstirred layer diffusion coefficient; Lus: Unstirred layer thickness; F: Intestinal convective flow; P: Permeability for DC model; $\mathrm{P}_{\mathrm{M}}$ : AM permeability for case where $\mathrm{F}_{\mathrm{A}}$ of dose is absorbed; $\mathrm{R}$ : Intestinal radius; L: Intestinal length; $\mathrm{S}$ : Surface area $=2 \pi \mathrm{rL} ; \mathrm{V}$ : Volume $=\pi \mathrm{r}^{2} \mathrm{~L}$; $\mathrm{N}$ : Number of finite segments in numerical solution; $\triangle \mathrm{P}: \mathrm{PS} / \mathrm{N} ; \Delta \mathrm{V}: \mathrm{V} / \mathrm{N}$;
De: $\pi r^{2} D N / L ;$ Dose: Total oral dose; $F_{A}$ : Fraction of dose absorbed; $\mathrm{I}_{G}(\mathrm{t})$ : Convective solute input from stomach; $E_{D c}$ : $D C$ flux from small to large intestine; $A_{D C}(t)$ : $D C$ cumulative amount leaving small intestine; $A_{M}$ : AM cumulative amount absorbed for case where $F_{A}$ of dose is absorbed; $E_{H}$ : Fractional liver extraction; $E_{1}$ : Fractional intestinal mucosal extraction; $\mathrm{Cl}_{\mathrm{H}}$ : Liver clearance; $\mathrm{Q}_{\mathrm{H}}$ : Liver blood flow; $\mathrm{M}$ : Amount absorbed $=\mathrm{F}_{\mathrm{A}}$ Dose; $M_{S}$ : AM amount entering the systemic circulation; $R_{D C}$ : $D C$ rate of intestinal absorption; R: AM rate of intestinal absorption for case where $100 \%$ absorbed in small intestine; $R_{M}$ : $A M$ rate of absorption for case where $F_{A}$ of dose is absorbed; $R_{S M}$ : AM rate of absorption corrected for intestinal and liver extraction; $c(x, t)$ : DC concentration at position $x$ at time t; $C(\mathrm{t})$ : "averaged" $A M$ concentration; $C_{\text {oral }}$ : Experimental blood concentration following an oral dose; $T_{F}$ : $D C$ convective time constant; $T_{D}$ : $D C$ dispersion time constant; $T_{p}$ : Intestinal permeability time constant; $T_{G}$ : Gastric emptying time constant; pKa: Acid dissociation constant; $P_{\text {ow: }}$ Octanol/water partition; log D: log Pow at $\mathrm{pH}=7.4$.

\section{Competing interests}

The author declares that he has no competing interests.

\section{Authors' contributions}

DGL is the sole contributor to this work.

Received: 17 December 2012 Accepted: 10 June 2013

Published: 24 June 2013

\section{References}

1. Egan WJ, Lauri G: Prediction of intestinal permeability. Adv Drug Deliv Rev 2002, 54(3):273-289.

2. Zhao $\mathrm{YH}$, Le J, Abraham MH, Hersey A, Eddershaw PJ, Luscombe CN, Butina D, Beck G, Sherborne B, Cooper I, et al: Evaluation of human intestinal absorption data and subsequent derivation of a quantitative structureactivity relationship (QSAR) with the Abraham descriptors. J Pharm Sci 2001, 90(6):749-784.

3. Amidon $K S$, Langguth $P$, Lennernas $H, Y u L$, Amidon $G L$ : Bioequivalence of oral products and the biopharmaceutics classification system: science, regulation, and public policy. Clin Pharmacol Ther 2011, 90(3):467-470.

4. Dahan A, Lennernas H, Amidon GL: The fraction dose absorbed, in humans, and high jejunal human permeability relationship. Molecular pharmaceutics 2012, 9(6):1847-1851.

5. Soderholm JD, Olaison G, Kald A, Tagesson C, Sjodahl R: Absorption profiles for polyethylene glycols after regional jejunal perfusion and oral load in healthy humans. Dig Dis Sci 1997, 42(4):853-857.

6. Levitt DG: The use of a physiologically based pharmacokinetic model to evaluate deconvolution measurements of systemic absorption. BMC Clin Pharmacol 2003, 3:1

7. Levitt DG: PKQuest_Java: free, interactive physiologically based pharmacokinetic software package and tutorial. BMC research notes 2009, 2:158

8. Sparacino G, Pillonetto G, Capello M, De Nicolao G, Cobelli C: WINSTODEC: a stochastic deconvolution interactive program for physiological and pharmacokinetic systems. Comput Methods Programs Biomed 2002, 67(1):67-77.

9. Verotta D: Estimation and model selection in constrained deconvolution. Ann Biomed Eng 1993, 21(6):605-620.

10. Agoram B, Woltosz WS, Bolger MB: Predicting the impact of physiological and biochemical processes on oral drug bioavailability. Adv Drug Deliv Rev 2001, 50(Suppl 1):S41-S67.

11. Yu LX, Amidon GL: A compartmental absorption and transit model for estimating oral drug absorption. Int J Pharm 1999, 186(2):119-125.

12. Ni PF HONFH, Fox JL, Leuenberger $H$, Higuchi $H$ l: Theoretical model studies of intestinal drug absorption V. Non-steady-state fluid flow and absorption. Int J Pharm 1980, 5:33-47.

13. Collins PJ, Horowitz M, Cook DJ, Harding PE, Shearman DJ: Gastric emptying in normal subjects-a reproducible technique using a single scintillation camera and computer system. Gut 1983, 24(12):1117-1125.

14. George JD: New clinical method for measuring the rate of gastric emptying: the double sampling test meal. Gut 1968, 9(2):237-242.

15. Wu CY, Benet LZ, Hebert MF, Gupta SK, Rowland M, Gomez DY, Wacher VJ: Differentiation of absorption and first-pass gut and hepatic metabolism in humans: studies with cyclosporine. Clin Pharmacol Ther 1995, 58(5):492-497.

16. Press WH, Teukolsky SA, Vetterling WT, Flannery BP: Numerical Recipes in C. 2nd edition. Cambridge: Cambridge University Press; 1992. 
17. Poulin P, Schoenlein K, Theil FP: Prediction of adipose tissue: plasma partition coefficients for structurally unrelated drugs. J Pharm Sci 2001 90(4):436-447

18. Lennernas $\mathrm{H}$ : Intestinal permeability and its relevance for absorption and elimination. Xenobiotica 2007, 37(10-11):1015-1051.

19. Miller MS, Galligan JJ, Burks TF: Accurate measurement of intestinal transit in the rat. J Pharmacol Methods 1981, 6(3):211-217.

20. Yu LX, Amidon GL: Characterization of small intestinal transit time distribution in humans. Int J Pharm 1998, 171(2):157-163.

21. Caride VJ, Prokop EK, Troncale FJ, Buddoura W, Winchenbach K, McCallum RW: Scintigraphic determination of small intestinal transit time: comparison with the hydrogen breath technique. Gastroenterology 1984 86(4):714-720

22. Davis SS, Hardy JG, Fara JW: Transit of pharmaceutical dosage forms through the small intestine. Gut 1986, 27(8):886-892.

23. Yang J, Jamei M, Yeo KR, Tucker GT, Rostami-Hodjegan A: Prediction of intestinal first-pass drug metabolism. Curr Drug Metab 2007, 8(7):676-684.

24. Clements JA, Heading RC, Nimmo WS, Prescott LF: Kinetics of acetaminophen absorption and gastric emptying in man. Clin Pharmacol Ther 1978, 24(4):420-431.

25. Heading RC, Nimmo J, Prescott LF, Tothill P: The dependence of paracetamol absorption on the rate of gastric emptying. Br J Pharmacol 1973, 47(2):415-421.

26. Ogungbenro K, Vasist L, Maclaren R, Dukes G, Young M, Aarons L: A semi-mechanistic gastric emptying model for the population pharmacokinetic analysis of orally administered acetaminophen in critically ill patients. Pharm Res 2011, 28(2):394-404.

27. Ameer B, Divoll M, Abernethy DR, Greenblatt DJ, Shargel L: Absolute and relative bioavailability of oral acetaminophen preparations. J Pharm Sci 1983, 72(8):955-958.

28. Divoll M, Ameer B, Abernethy DR, Greenblatt DJ: Age does not alter acetaminophen absorption. J Am Geriatr Soc 1982, 30(4):240-244.

29. Eandi M, Viano I, Ricci Gamalero S: Absolute bioavailability of paracetamol after oral or rectal administration in healthy volunteers. Arzneimittelforschung 1984, 34(8):903-907.

30. Mitchell DY, Barr WH, Eusebio RA, Stevens KA, Duke FP, Russell DA, Nesbitt JD, Powell JH, Thompson GA: Risedronate pharmacokinetics and intraand inter-subject variability upon single-dose intravenous and oral administration. Pharm Res 2001, 18(2):166-170.

31. Hui YF, Kolars J, Hu Z, Fleisher D: Intestinal clearance of H2-antagonists. Biochem Pharmacol 1994, 48(2):229-231.

32. Walkenstein SS, Dubb JW, Randolph WC, Westlake WJ, Stote RM, Intoccia AP: Bioavailability of cimetidine in man. Gastroenterology 1978, 74(2 Pt 2):360-365.

33. Heykants J, Hendriks R, Meuldermans W, Michiels M, Scheygrond H, Reyntjens $\mathrm{H}$ : On the pharmacokinetics of domperidone in animals and man. IV. The pharmacokinetics of intravenous domperidone and its bioavailability in man following intramuscular, oral and rectal administration. Eur J Drug Metab Pharmacokinet 1981, 6(1):61-70.

34. Gray VA, Dressman JB: Change of $\mathrm{pH}$ requirement for simulated intestinal fluid TS. Pharmacopeial Forum 1996, 22(1):1943-1945.

35. Ovesen L, Bendtsen F, Tage-Jensen U, Pedersen NT, Gram BR, Rune SJ: Intraluminal $\mathrm{pH}$ in the stomach, duodenum, and proximal jejunum in normal subjects and patients with exocrine pancreatic insufficiency. Gastroenterology 1986, 90(4):958-962.

36. Evans DF, Pye G, Bramley R, Clark AG, Dyson TJ, Hardcastle JD: Measurement of gastrointestinal $\mathrm{pH}$ profiles in normal ambulant human subjects. Gut 1988, 29(8):1035-1041.

37. Lalezari D: Gastrointestinal pH profile in subjects with irritible syndrome. Ann Gastroenterol 2012, 25(4):1-5.

38. Avdeef A: Absorption and drug development. Solubility, permeability and charge state. Hoboken, New Jersey: John Wiley and Sons,Inc; 2003.

39. Kramer SD: Absorption prediction from physicochemical parameters. Pharm Sci Technology Today 1999, 2(9):373-380.

40. Pauli-Magnus C, Murdter T, Godel A, Mettang T, Eichelbaum M, Klotz U, Fromm MF: P-glycoprotein-mediated transport of digitoxin, alphamethyldigoxin and beta-acetyldigoxin. Naunyn Schmiedebergs Arch Pharmacol 2001, 363(3):337-343.

41. Dahan A, Amidon GL: Grapefruit juice and its constituents augment colchicine intestinal absorption: potential hazardous interaction and the role of p-glycoprotein. Pharm Res 2009, 26(4):883-892.

42. Jung N, Lehmann C, Rubbert A, Knispel M, Hartmann P, van Lunzen J, Stellbrink HJ, Faetkenheuer G, Taubert D: Relevance of the organic cation transporters 1 and 2 for antiretroviral drug therapy in human immunodeficiency virus infection. Drug Metab Dispos 2008, 36(8):1616-1623.

43. Levitt DG, Hakim AA, Lifson N: Evaluation of components of transport of sugars by dog jejunum in vivo. Am J Physiol 1969, 217(3):777-783.

44. Rolston DD, Mathan Vl: Xylose transport in the human jejunum. Dig Dis Sci 1989, 34(4):553-558.

45. Csaky TZ, Ho PM, Csaky TZ, Ho PM: Intestinal transport of D-xylose. Proceedings of the Society for Experimental Biology and Medicine Society for Experimental Biology and Medicine (New York, NY) 1965, 120(2):403-408.

46. Tsuda M, Terada T, Irie M, Katsura T, Niida A, Tomita K, Fujii N, Inui K: Transport characteristics of a novel peptide transporter 1 substrate, antihypotensive drug midodrine, and its amino acid derivatives. J Pharmacol Exp Ther 2006, 318(1):455-460.

47. Rowland M: Influence of route of administration on drug availability. J Pharm Sci 1972, 61(1):70-74

48. Bochner F, Williams DB, Morris PM, Siebert DM, Lloyd JV: Pharmacokinetics of low-dose oral modified release, soluble and intravenous aspirin in man and effects on platelet function. Eur J Clin Pharmacol 1988, 35(3):287-294.

49. Hogben CA, Tocco DJ, Brodie BB, Schanker LS: On the mechanism of intestinal absorption of drugs. J Pharmacol Exp Ther 1959, 125(4):275-282.

50. Levitt MD, Strocchi A, Levitt DG: Human jejunal unstirred layer: evidence for extremely efficient luminal stirring. Am J Physiol 1992, 262(3 Pt 1): G593-G596

51. Rechkemmer G, Wahl M, Kuschinsky W, von Engelhardt W: pH-microclimate at the luminal surface of the intestinal mucosa of guinea pig and rat. Pflugers Arch 1986, 407(1):33-40.

52. Takanaga H, Tamai I, Tsuji A: pH-dependent and carrier-mediated transport of salicylic acid across Caco-2 cells. J Pharm Pharmacol 1994, 46(7):567-570

53. Tamai I, Takanaga H, Maeda H, Yabuuchi H, Sai Y, Suzuki Y, Tsuji A: Intestinal brush-border membrane transport of monocarboxylic acids mediated by proton-coupled transport and anion antiport mechanisms. J Pharm Pharmacol 1997, 49(1):108-112.

54. Takagi M, Taki Y, Sakane T, Nadai T, Sezaki H, Oku N, Yamashita S: A new interpretation of salicylic acid transport across the lipid bilayer: implications of $\mathrm{pH}$-dependent but not carrier-mediated absorption from the gastrointestinal tract. J Pharmacol Exp Ther 1998, 285(3):1175-1180.

55. Fagerholm $\mathrm{U}$, Lennernas $\mathrm{H}$ : Experimental estimation of the effective unstirred water layer thickness in the human jejunum, and it importance in oral drug absorption. Eur J Pharm Sci 1995, 3:247-253.

56. Mackenzie NM: Comparison of the metabolic activities of enterocytes isolated from different regions of the small intestine of the neonate. Biol Neonate 1985, 48(5):257-268.

57. Lennernas H: Human intestinal permeability. J Pharm Sci 1998, 87(4):403-410.

58. Knutson T, Fridblom P, Ahlstrom H, Magnusson A, Tannergren C, Lennernas $\mathrm{H}$ : Increased understanding of intestinal drug permeability determined by the LOC-I-GUT approach using multislice computed tomography. Mol Pharm 2009, 6(1):2-10

59. Larregieu CA, Benet LZ: Drug discovery and regulatory considerations for improving in silico and in vitro predictions that use caco- 2 as a surrogate for human intestinal permeability measurements. AAPS J 2013, 15(2):483-497.

60. Thomas S, Brightman F, Gill H, Lee S, Pufong B: Simulation modelling of human intestinal absorption using Caco-2 permeability and kinetic solubility data for early drug discovery. J Pharm Sci 2008, 97(10):4557-4574.

61. Hidalgo IJ, Hillgren KM, Grass GM, Borchardt RT: Characterization of the unstirred water layer in Caco-2 cell monolayers using a novel diffusion apparatus. Pharm Res 1991, 8(2):222-227.

\section{doi:10.1186/2050-6511-14-34}

Cite this article as: Levitt: Quantitation of small intestinal permeability during normal human drug absorption. BMC Pharmacology and Toxicology 2013 14:34. 